Check for updates

Cite this: Mater. Adv., 2021, 2, 6901

Received 1st August 2021,

Accepted 9th September 2021

DOI: 10.1039/d1ma00675d

rsc.li/materials-advances

\title{
Advances in implant surface modifications to improve osseointegration
}

\author{
Guang Zhu, ab Guocheng Wang (D) *a and Jiao Jiao Li (D)*bc
}

\begin{abstract}
Metallic biomaterials are widely used in implants to strengthen, repair, or replace damaged bone tissue, and their material characteristics have direct influences on short- and long-term implant performance. Of these, titanium and its alloys are the most widely applied due to their superior corrosion resistance, biocompatibility, and mechanical properties, such as in joint replacements, dental implants, and spinal fusion cages. However, $\mathrm{Ti}$ and $\mathrm{Ti}$ alloys are bioinert materials that have difficulty in binding directly to bone tissue after implantation, due to a lack of osteoconductive and osteoinductive properties. Bacterial adhesion and colonisation at the implantation site may also lead to infection-associated complications. The surface of the titanium implant directly interfaces with blood, cells, and tissues in vivo, and the surface properties can have profound influences on protein- and cell-based interactions that then promote or impede osseointegration. Therefore, the material surface morphology, chemistry and antibacterial function are key parameters in implant design, and contribute to determining the long-term success of the implant. In this review, we systematically present the latest advances in surface modification techniques for orthopaedic implants, including mechanical, physical, chemical, and biological modification. We also analyse and compare different surface modification approaches, including drug loading, metallic element doping, and bionic coatings, as well as topographical modifications such as nanotubes, nanopores and nanowires. Finally, we present a critical analysis and future perspectives on the use of surface modifications to improve the osseointegration and antibacterial properties of orthopaedic implants.
\end{abstract}

\section{Introduction}

In recent decades, the worldwide demand for orthopaedic implants has continued to increase at an alarming rate. For Australia alone, the incidence rate of primary total hip arthroplasty (THA) is predicted to increase by $66 \%$ between 2013 and 2046 according to a conservative projection model. ${ }^{1}$ In the US, the total number of hip and knee replacements has reached 7 million cases per year. ${ }^{2}$ Revision surgeries due to peri-implant diseases or implant failure also increase the demand for orthopaedic implants. According to a crosssectional analysis, one-quarter of patients and one-sixth of implants will develop peri-implantitis after 11 years. $^{3}$ A statement from the third EAO consensus conference 2012 stated that approximately one-fifth of patients will suffer from

\footnotetext{
${ }^{a}$ Research Center for Human Tissues \& Organs Degeneration, Shenzhen Institute of Advanced Technology, Chinese Academy of Science, Shenzhen, Guangdong, 518055, China. E-mail: gc.wang@siat.ac.cn; Tel: +86-755-86392561

${ }^{b}$ Kolling Institute, Faculty of Medicine and Health, University of Sydney, St Leonards, NSW 2065, Australia

${ }^{c}$ School of Biomedical Engineering, Faculty of Engineering and IT,

University of Technology Sydney, NSW 2007, Australia.

E-mail: jiaojiao.li@uts.edu.au; Tel: +61-2-95149232
}

peri-implantitis within 5 years of implant placement. ${ }^{4}$ To meet this significant demand, a wide range of biomaterials have been used and are being developed for orthopaedic implants, including metallic, ceramic, and polymeric materials. ${ }^{5}$ Metallic biomaterials have the advantages of high strength and toughness, easy processing, and good biocompatibility. Ceramic biomaterials have relatively poor mechanical properties, but they have stable chemical properties and are biocompatible or bioactive, leading to their primary use as implant coatings. Polymeric biomaterials generally have the advantages of biological aging resistance and high purity, but their mechanical properties are often insufficient for hard tissue replacement and the majority are biologically inert.

Among the clinically applied metallic biomaterials, titanium (Ti) and its alloys, such as Ti6Al4V, are the most popular candidates for bone implants due to their excellent mechanical properties (high mechanical strength, low density, immunity to corrosion) and superior biocompatibility, compared to conventional materials such as stainless steel $316 \mathrm{~L}$ and cobalt-chromium (CoCr) alloys. ${ }^{6,7}$ However, the direct use of Ti and its alloys as implant materials is subject to several limitations. Firstly, their inherent bioinertness leads to a high rate of implant failure as they lack the ability to form chemical bonds 
with surrounding tissues. ${ }^{8,9} \mathrm{Ti}$ forms only a physical bond with bone tissue, the stability of which is much lower than chemical osseous bonding, leading to a higher risk of implant loosening or failure during long-term use. ${ }^{10}$ Secondly, Ti lacks natural antimicrobial properties, easily allowing bacterial colonisation during the early stages of implantation. ${ }^{11}$ Following colonisation, the bacteria can grow to form a biofilm that interferes with the function of antibiotics and leads to subsequent infection. ${ }^{11}$ The infection rate of implants is also influenced by the surgical site and procedure. For example, the chance of infection is $2-30 \%$ for transcutaneous fracture fixation pins, and $13 \%$ for bone supplementation. ${ }^{12}$ The situation is further complicated by drug resistance in common pathogens such as Escherichia coli and Staphylococcus aureus, and antibiotic-resistant infections are increasing globally at an alarming rate. ${ }^{13}$ Antibiotic-resistant bacteria are estimated to cause at least 2 million infections and 23,000 deaths per year in the US, incurring a cost of \$55-70 billion. ${ }^{14}$ Moreover, patients with infections associated with orthopaedic implants are reported to have worse clinical outcomes when the infection is caused by antibiotic-resistant compared to antibiotic-sensitive bacteria. ${ }^{14}$ Thirdly, the corrosion resistance of $\mathrm{Ti}$ and its alloys still needs further improvement, since ion release due to surface corrosion can lead to toxicity and bone loss. ${ }^{10,15}$ Although a titanium oxide film is easily generated on the surface of Ti implants, which is relatively stable, ion release can still occur after this thin film is eroded off. For instance, corrosion in Ti6Al4V implants can lead to the release of $\mathrm{Al}$ and $\mathrm{V}$, where $\mathrm{Al}$ is linked to brain dementia, and $\mathrm{V}$ is harmful to the surrounding cells and can cause metal sensitisation. ${ }^{16,17}$

To address the limitations of Ti and its alloys as implant materials, improvements in biomedical performance (such as interactions with bone-related cells) can be introduced by modifying their surface roughness and morphology, as well as chemical properties. ${ }^{18}$ Osseointegration refers to the strong bond formed between an implant and osseous tissue, a concept first described by Branemark in the 1980s. ${ }^{19}$ The ability of an implant to achieve osseointegration to a large extent determines its long-term success in the body. Since the implant surface is in direct contact with cells, tissues and blood in vivo, material surface properties play a significant role in osseointegration and hence implant performance. Therefore, surface modification of metal implants is an effective approach to improve bone cell adhesion, proliferation, and differentiation when fast healing is needed. ${ }^{20}$ The purpose of surface modification is to simultaneously maintain the excellent mechanical properties and biocompatibility of the implant, while also optimising its antibacterial properties, corrosion resistance, and bioactivity. As such, surface modification is a primary and one of the most rapidly advancing areas in the development and optimisation of Ti and its alloys for biomedical applications.

The surface modification of materials can focus on several aspects, including the topographical structure, chemical composition, surface energy, hydrophilicity and hydrophobicity, and phosphate forming ability of materials. ${ }^{21,22}$ The most common strategy is to design and prepare a bioactive coating to enhance implant osseointegration and associated biological processes. Various bioactive implant coatings have been applied, such as hydroxyapatite (HA), other bio-ceramics, and bioactive oxides. ${ }^{23-25}$ Among the existing bioactive oxide coatings, such as $\mathrm{TiO}_{2}, \mathrm{ZrO}_{2}, \mathrm{Al}_{2} \mathrm{O}_{3}, \mathrm{CuO}, \mathrm{ZnO}$ and some other oxides, titanium dioxide has been widely used for modifying the surface of Ti alloy implants due to its excellent chemical stability, biocompatibility, and strong binding with the Ti alloy substrate. ${ }^{25-27}$ Moreover, $\mathrm{TiO}_{2}$ has a bactericidal effect due to its photocatalytic properties, indicating potential applications as an antibacterial implant coating. ${ }^{28}$ Other interesting structures have been developed such as $\mathrm{TiO}_{2}$ nanotubes, which may be applied for drug delivery, anti-inflammatory functions, and osteogenesis. ${ }^{29}$ Interestingly, by adjusting the nanotube diameter $(15,60$, or $120 \mathrm{~nm}$ ) on the Ti surface, the blood clotting characteristics of the implant can be modulated to improve its immune response, rendering the implant anti-thrombotic and improving its ability to encourage osseointegration and bone regeneration. ${ }^{30}$

Other interesting developments in the area of surface modification for bone implants include designs that functionalise the surface with various abilities to promote osteogenesis, such as angiogenesis, production of reactive oxygen species (ROS), macrophage regulation, and antimicrobial effects. ${ }^{31-33} \mathrm{Ti}$ alloy surfaces with composite functions have been designed to facilitate implant osseointegration by responding to different biological environments. $^{34,35}$ Furthermore, the performance of Ti implant surfaces in patients with specific disease conditions, such as type II diabetes, and their improvement strategies have been studied. ${ }^{36}$

In this review, we present the latest developments in the surface modification of Ti and Ti alloy implants (Fig. 1), through research articles published mostly within the last five years. We have classified various surface modification approaches into four broad categories: mechanical modification, physical modification, chemical modification, and biological modification. Some modification methods combined features across categories, and were classified according to their primary concept. We acknowledge other recently published impactful reviews on the topic of surface modification for biomaterial implants, which have provided insightful perspectives into surface modification of $\mathrm{Ti}$ and its alloys without a specific focus on their biomedical applications, ${ }^{37}$ or discussed surface modification to promote osseointegration without focusing on metal implant materials. ${ }^{38,39}$ Other reviews have focused on specific aspects of surface modification in $\mathrm{Ti}$ and Ti alloys for encouraging bone growth, such as the surface corrosion properties, ${ }^{40,41}$ biological resemblance to bone, ${ }^{42}$ and antibacterial function. ${ }^{43}$ Our review provides a comprehensive overview of the latest advances in surface modification methods of $\mathrm{Ti}$ and $\mathrm{Ti}$ alloy implants to improve their osseointegration, covering different mechanisms of modification and an extensive sample of the most recent studies.

\section{Surface modification methods}

\subsection{Mechanical modification methods}

Mechanical modification mainly involves relatively basic treatment methods such as grinding, polishing, sandblasting, and 


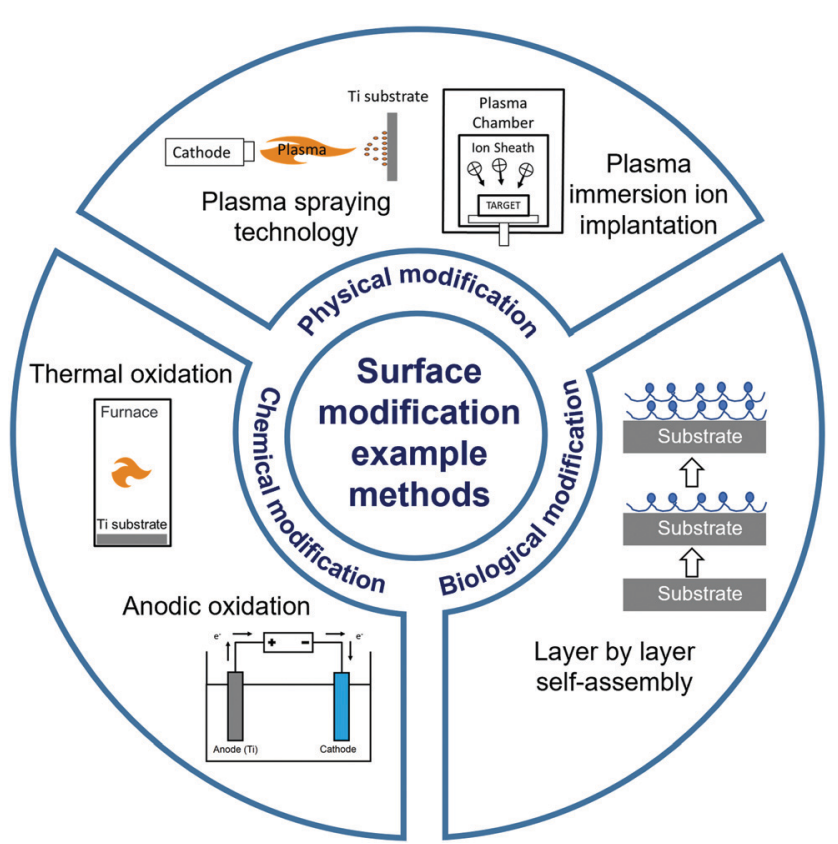

Fig. 1 Schematic overview of the categories and examples of surface modification methods discussed in this review.

vacuum annealing. ${ }^{41}$ These methods are used to make the biomaterial surface smooth or rough, thereby modifying its properties including biological adhesion, surface hydrophilicity, bone tissue affinity, electrical potential energy, and surface tension. Mechanical modification can also be used to remove surface contamination and increase the binding strength of the substrate for subsequent treatment. For instance, Bacchelli et al. ${ }^{44}$ compared the bone integration ability of Ti implants that were zirconia sandblasted ( $\mathrm{Zr}-\mathrm{SL})$, with control, titanium oxide plasma sprayed (TPS), and alumina sandblasted (Al-SL) implants in sheep at 2, 4 and 12 weeks after insertion. The $\mathrm{Zr}-\mathrm{SL}$ and Al-SL implants achieved similar performance, which promoted better peri-implant new bone formation compared to control and TPS. Barranco et al. ${ }^{45}$ prepared and characterised polished, finely blasted and coarsely blasted Ti6Al4V surfaces. The blasting process was found to alter the surface morphology and chemical properties, leading to an increase in the capacitance values of the blasted samples, but did not change their corrosion behaviour. Günay-Bulutsuz et al. $^{46}$ produced ultrafine-grain (UG) commercial purity (CP) Ti from $99.5 \%$ pure Ti Grade 4 by equal angular channel pressing. Sandblasting the sample surfaces was found to produce a more favourable grain size and surface roughness, which promoted the attachment and proliferation of human gingival fibroblast cells. Recently, Lowe et al. ${ }^{47}$ studied the biocompatibility of UG and coarse-grain (CG) CP Ti with or without polishing treatment, and concluded that the UG and polished Ti could enhance the proliferation of MC3T3-E1 pre-osteoblastic cells. The average grain boundary length per surface-attached cell was also identified as a new biophysical parameter that was correlated with cell proliferation. Shi et $a l .{ }^{48}$ designed a hydrothermal sterilisation (HS) method by placing Ti samples in pure water at $121{ }^{\circ} \mathrm{C}$ for 20 minutes, followed by storing them in the same water until utilisation, which would reduce hydrocarbon contamination on Ti surfaces encountered during traditional sterilisation and storage. This method was found to produce super-hydrophilicity on the sandpaper-polished Ti surface, which improved the initial osteoblast response compared with autoclaving.

Mechanical modification is often used as a pre-treatment strategy to improve the outcomes of subsequent surface modification methods. Miao et al. ${ }^{49}$ systematically evaluated the effects of Ti surface nanotopography on the behaviour of a range of human cells as well as bacteria, and suggested that changes in nanotopography could promote bone and soft tissue healing. A smooth Ti surface (Smooth) was first prepared by polishing, and then used to fabricate nano-rough (Nano) and micro-rough (Micro) surfaces by alkali-hydrothermal treatment and sandblasting and acid etching (SLA), respectively. The different surfaces influenced the osteogenic activity of MG-63 cells $($ Nano $=$ Micro $>$ Smooth), and the attachment ability of human gingival epithelial cells (Nano $>$ Smooth $>$ Micro) and human gingival fibroblasts (Nano $=$ Micro $>$ Smooth). Moreover, changes in nanotopography did not affect macrophage polarisation $($ Nano $=$ Micro $=$ Smooth $)$, but did affect Streptococcus mutans attachment (Nano $<$ Smooth $<$ Micro). Wang et $a l^{50}$ pre-treated Ti6Al4V flakes with sandpaper of different meshes, followed by treatment in three groups: grinding, sandblasting and etching, or nanosecond laser (Fig. 2). When tested using rat bone marrow-derived mesenchymal stem cells (BMSCs), it was found that cell proliferation was not affected by surface roughness alone, since cells tended to exhibit higher proliferation on flatter surfaces with a larger surface area. The spread of the cell cytoskeleton was suggested to be influenced by the surface energy barrier, where samples with micro-groove arrays produced by nanosecond laser treatment induced cells to form a cytoskeleton with higher aspect ratio.

\subsection{Physical modification methods}

Physical modification methods typically involve no or only a minor chemical reaction during the whole surface modification process, and they include plasma spraying technology (PST), plasma immersion ion implantation (PIII), and laser cladding. Physical modification is typically used for the dry transformation of passive inert implants into smart implant surfaces that actively instruct the physiological environment towards bone tissue regeneration. ${ }^{21}$

2.2.1 Plasma spraying technology (PST). PST uses a plasma arc driven by a direct current as the heat source to ionise inert gas (plasma) and generate heat. The high-temperature plasma flame causes the spraying material, such as ceramics, metals, alloys, or other materials, to reach a molten or semi-molten state, which is then sprayed onto a pre-treated implant surface at high speed to form a firm coating. ${ }^{51}$ As a surface coating technology, PST has the advantages of a fast deposition rate, large deposition thickness, and low cost.

Hydroxyapatite (HA) coatings, which are commonly used in clinical practice to improve osseointegration, are formed by spraying HA particles onto the implant surface at high temperature and 

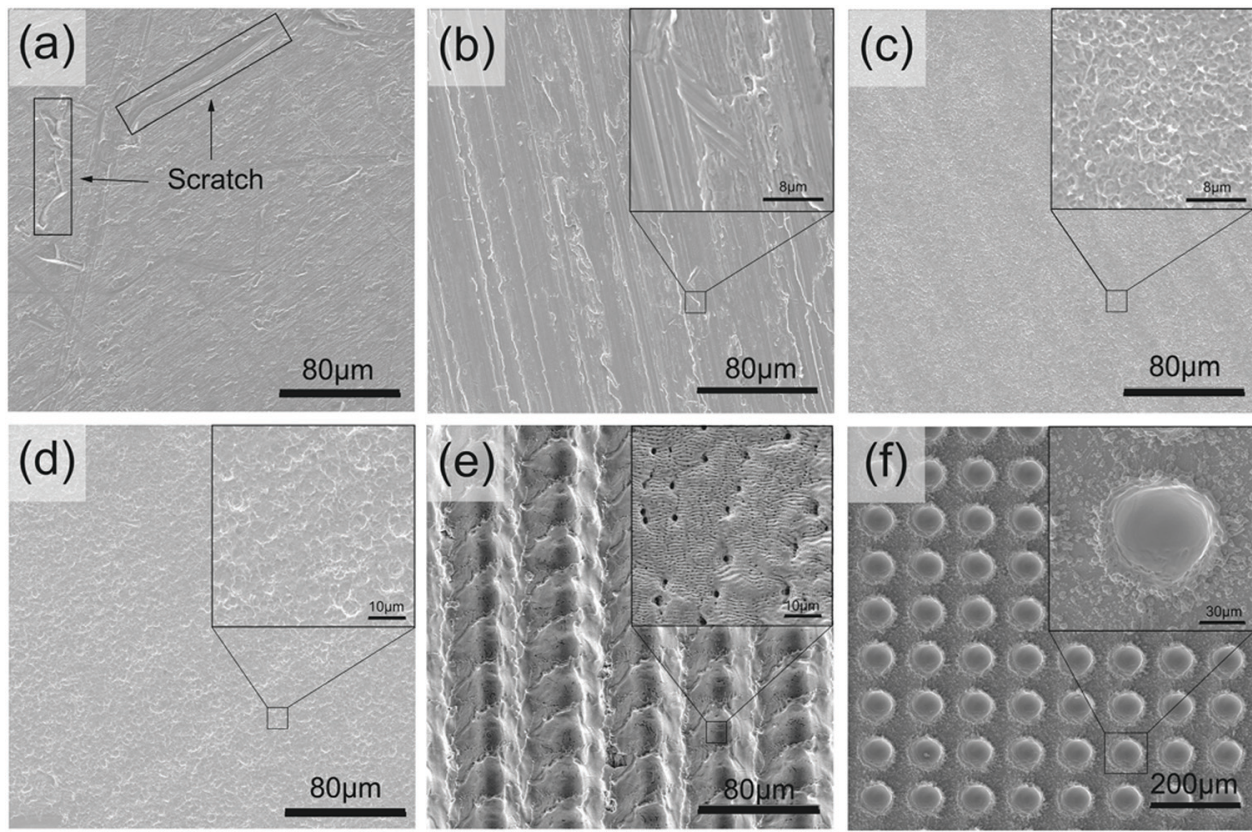

(A1)

(A2)

(A3)
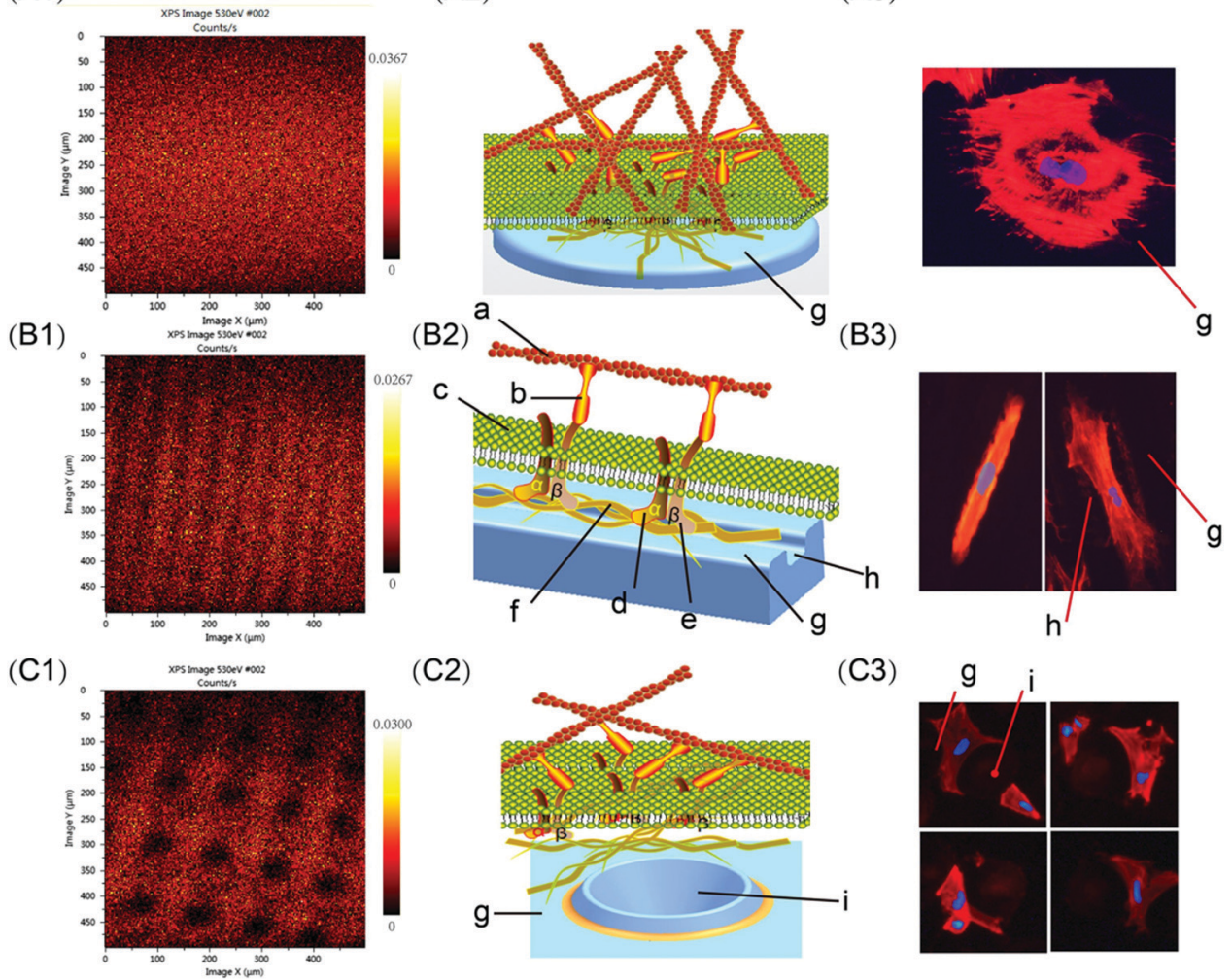

(C2)

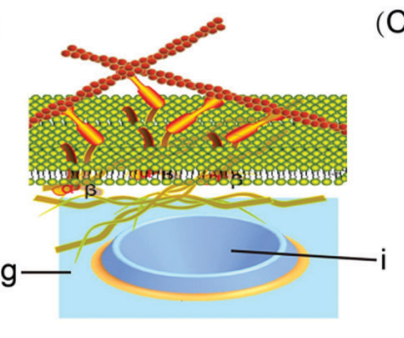

(C3)

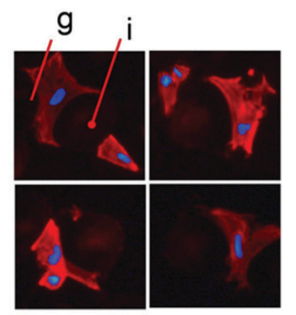

Fig. 2 Different surface morphologies (top panel) produced by grinding ( $a$ and b), blasting and etching (c and d), and nanosecond laser (e and f), inducing differences in focal adhesion formation and cytoskeletal morphology of cells (bottom panel; A, B and C correspond to surfaces a, e and f respectively from the top panel)..$^{50}$ Reprinted with permission. Copyright 2020, Elsevier.

cooling them rapidly. ${ }^{52}$ However, the HA coating has some disadvantages, a primary one being that the coating binds easily to bone tissue but has a low bonding strength to the metal alloy substrate. When sprayed at high temperatures, HA is prone to structural changes or even degradation, and its coefficient of thermal expansion (CTE) differs greatly from that of Ti and Ti alloys. These factors affect the bonding strength of the coating, which may lead to poor adhesion or delamination at the interface between the coating and the substrate, and even implant failure due to cracking and peeling of the coating. ${ }^{53}$

To better meet the requirements of clinical application, Fomin et al. ${ }^{54}$ investigated induction pre-heating (from 200 to 
$1000{ }^{\circ} \mathrm{C}$ ) to improve the structural and mechanical properties of HA coatings on Ti implants using PST. Pre-heating the sample in the temperature range of $400-600{ }^{\circ} \mathrm{C}$ produced uniform nanostructures on the surface. The modified HA coatings showed high hardness (0.9-1.2 GPa) and elastic modulus (7-16 GPa). However, the bonding force between the coating and the substrate was not tested. To improve the coatingsubstrate bonding force, post-heat treatment of the HA coating can be applied. As an example, Ullah et $a .^{55}$ synthesised (Sr, Zn)-HA powders by combining heat treatment with the hydrothermal method, and used PST to prepare $\mathrm{Zn}$ - and Sr-doped HA coatings on a Ti6Al4V substrate. $\mathrm{Zn}$ ions were used to provide antibacterial properties, and $\mathrm{Sr}$ ions were included to reduce the cytotoxicity of $\mathrm{Zn}$. Post-heat treatment was performed on the $\mathrm{Zn}$ - and Sr-doped HA coatings at 500 and $600{ }^{\circ} \mathrm{C}$ for 3 hours. The results indicated that the ( $\left.\mathrm{Sr}, \mathrm{Zn}\right)-\mathrm{HA}$ coating post-treated at $500{ }^{\circ} \mathrm{C}$ had excellent mechanical properties, biocompatibility, and antibacterial properties. The coating post-treated at $600{ }^{\circ} \mathrm{C}$ showed cytotoxicity to MC3T3-E1 cells which limited its biomedical applications, but had remarkable mechanical and antibacterial properties. To reduce the mismatch in CTE between the metal alloy and the HA coating, Ke et $a .^{56}$ fabricated a gradient HA layer using laser engineered net shaping (LENS ${ }^{\mathrm{TM}}$ ) between the Ti6Al4V substrate and the PST HA coating (Fig. 3A). It was found that this middle layer should have a small wt\% of HA to reduce the CTE mismatch between the overlying coating and the underlying substrate, and increase the bonding force of the coating. The middle layer did not affect the surface roughness of the overlying coating. In addition, $\mathrm{MgO}$ and $\mathrm{Ag}_{2} \mathrm{O}$ were introduced into the overlying PST HA coating. $\operatorname{Ag}_{2} \mathrm{O}$ showed sustained antimicrobial activity against $E$. coli and $S$. aureus, while $\mathrm{MgO}$ had no significant effects on promoting bone formation. Other approaches for improving HA coating performance include producing composite coatings. Lahiri et $a{ }^{57}$ formed a HA-carbon nanotube (CNT) composite powder by spray drying, and plasma sprayed HA-4 wt \% CNT powder on a Ti6Al4V substrate to prepare the coating. This HA-CNT composite coating showed superior mechanical (higher wear resistance and less debris production) and biological (higher osteoblast activity and less cytotoxicity) properties compared to HA coating.

A drug-loaded coating can be applied to HA-coated Ti implants to further improve osseointegration. As an example, Sarkar and Bose ${ }^{58}$ designed a top coating loaded with curcumin and vitamin $\mathrm{K} 2$, which was applied on HA-coated Ti6Al4V implants. The dual drug solution containing dissolved curcumin and vitamin $\mathrm{K} 2$ was added on the top surface of implants overnight in the dark to form a drug coating above the HA coating. The dual drug loaded samples reduced the in vitro proliferation of attached osteosarcoma cells, as well as the survival rate of unattached cells by $92-95 \%$ compared to the control group. In a rat distal femur model, the drug loaded implant promoted osseointegration after 5 days of implantation compared to the control group. Further studies to evaluate long-term osseointegration and bone repair in large animal models are warranted.

$\mathrm{Sr}$ has been widely employed in bone tissue engineering due to its ability to promote osteogenesis. ${ }^{59} \mathrm{Xu}$ et al. ${ }^{60}$ produced $\mathrm{TiO}_{2}$ coatings using PST with different SrO-doping percentages, and found that the $20 \% \mathrm{SrO}^{-} \mathrm{TiO}_{2}$ coating showed the best ability to promote the proliferation and differentiation of rat BMSCs. The Sr ions showed a continuous release behaviour as modulated by their Sr configuration, either as interstitial atoms in solid solution ( $\left.\mathrm{TiySr}_{2-2 y} \mathrm{O}_{2}\right)$ or as strontium titanate $\left(\mathrm{SrTiO}_{3}\right)$. Zhang et al. ${ }^{61}$ prepared Sr-hardystonite (Sr-HT) ceramic $\left(\mathrm{Ca}_{2} \mathrm{Zn}\right.$ $\mathrm{Si}_{2} \mathrm{O}_{7}$ ) coatings on Ti6Al4V implants by PST, with hybrid micro-/ nano-scale structures. Both the coating-implant and coatingbone tissue adhesive bond strength were found to be improved. In vitro and in vivo experiments indicated the bioactivity of the coating and its ability to promote rapid bone formation in a canine model. The hybrid micro-/nano-scale structures promoted the adhesion of canine BMSCs, while bioactive ion release from the Sr-HT coating regulated BMSC differentiation. Strontium zinc silicate $\left(\mathrm{SZnS}, \mathrm{Sr}_{2} \mathrm{ZnSi}_{2} \mathrm{O}_{7}\right)$ has a strong mineralisation ability and can be applied in coatings and
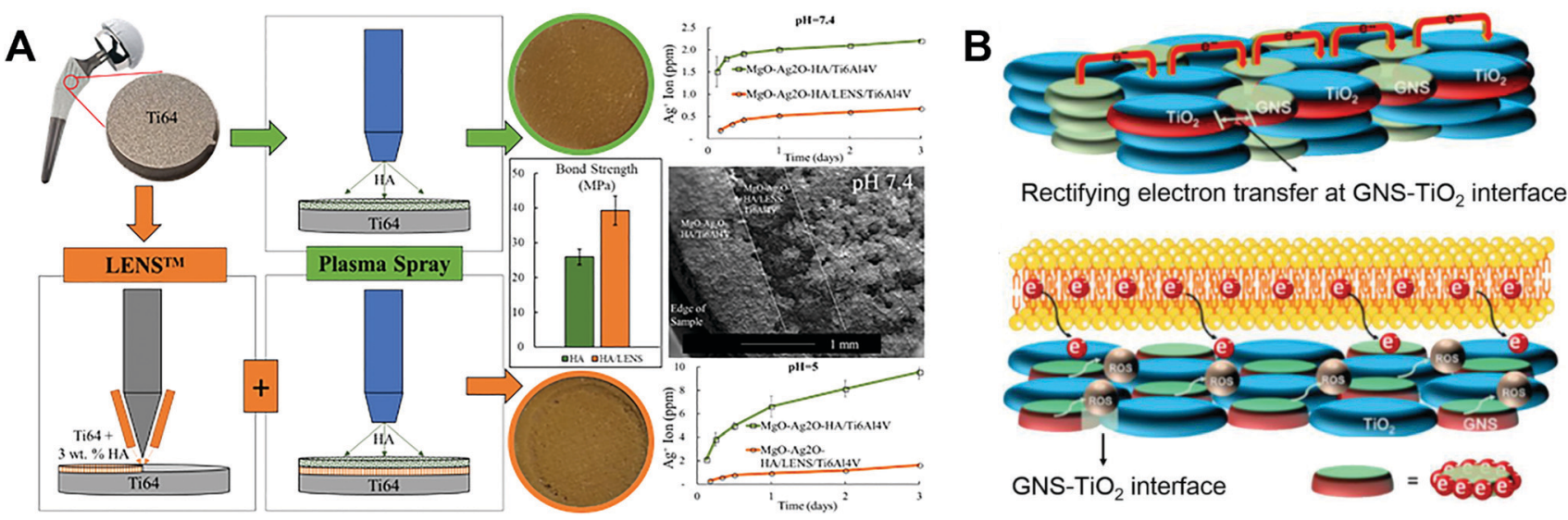

Fig. 3 Schematic illustration of (A) the fabrication process for a gradient HA layer by combining LENS ${ }^{\text {TM }}$ and PST, ${ }^{56}$ and (B) electron transfer mechanism leading to ROS generation in an antibacterial GNS $-\mathrm{TiO}_{2}$ coating fabricated using PST. ${ }^{31}$ Reprinted and adapted with permission. Copyright 2019 \& 2020 , Elsevier. 
scaffolds. ${ }^{62,63}$ Wang et al. ${ }^{62}$ produced a SZnS coating on Ti alloy samples using PST, and applied a modified autoclave sterilisation process whereby samples were immersed in a buffered solution containing $4.2 \mathrm{mM} \mathrm{HCO}_{3}{ }^{2-}$, to form biomorphic strontium carbonate $\left(\mathrm{SrCO}_{3}\right)$ on the coating surface. The subcellular topographical features of $\mathrm{SrCO}_{3}$ biomorphs were found to prevent the burst release of ions, promote osteoblast adhesion and collagen production, and upregulate their alkaline phosphatase (ALP) activity. SZnS preferentially releases Sr ions, leaving behind a silica-rich gel on the ceramic surface which results in an alkaline $\mathrm{pH}$ in the local area, thereby providing a growth condition for the bimorphic crystals. ${ }^{63}$ The nanostructured mineralised surfaces were found to promote osteogenic differentiation and induce increased new bone formation in a rabbit model compared to non-mineralised surfaces.

The role of reactive oxygen species (ROS) in modulating biological activity has been increasingly studied and applied in biomaterial design. ${ }^{64}$ Yang et al. ${ }^{31}$ designed an antibacterial graphene nanosheet (GNS)- $\mathrm{TiO}_{2}$ coating based on an electron transfer mechanism, which was fabricated on Ti alloy samples using PST. The combination of unpaired $\pi$ electrons of GNS and $\mathrm{Ti}$ atoms increased the electrical conductivity of the $\mathrm{TiO}_{2}$ surface. A bactericidal effect resulted from enhanced electron transfer from the bacterial cell membrane to the coating surface, and enrichment of electrons at the interface between the bacterial cell and the GNS- $\mathrm{TiO}_{2}$ coating. Specifically, an "electron sink" is created at the GNS and $\mathrm{TiO}_{2}$ interfaces, which can attract and store electrons extruded from bacterial cells due to Schottky barrier effects. Within the coating, the holes between $\mathrm{TiO}_{2}$ are surrounded by electrons, leading to ROS generation from oxidation reactions at the interface between bacteria and $\mathrm{TiO}_{2}$, resulting in a strong bactericidal effect (Fig. 3B).

2.2.2 Plasma immersion ion implantation (PIII). The PIII method produces a plasma in a specially designed vacuum chamber with different plasma sources, and injects the ion beam into an implant. The ion beam interacts physically and chemically with the atoms or molecules in the implant. The energy of the injected ions is gradually lost and the ions stay within the implant, causing changes in its surface composition, structure, and performance. Zhao et al. ${ }^{65}$ doped Si ions into $\mathrm{TiO}_{2}$ nanotubes on Ti implant surfaces by PIII. In vitro and in vivo experiments showed that the modified surface enhanced the production of osteogenesis-related proteins (ALP, Runx2), calcium deposition, and implant-tissue interface bonding strength.

A number of studies have implanted silver into Ti substrates as an inorganic antibacterial agent to combat periprosthetic infection. The bactericidal effect of $\mathrm{Ag}$ nanoparticles (NPs) doped in Ti surfaces is found to be independent of the release of silver ions. ${ }^{66,67}$ Qin et al. ${ }^{66}$ immobilised Ag NPs on the surface of Ti implants by PIII to endow the implants with antibacterial activity. The Ag NPs showed no obvious cytotoxicity, reduced biofilm formation of Staphylococcus epidermidis by inhibiting bacterial adhesion and icaAD gene transcription, and were effective against several cycles of bacterial attack in vitro.
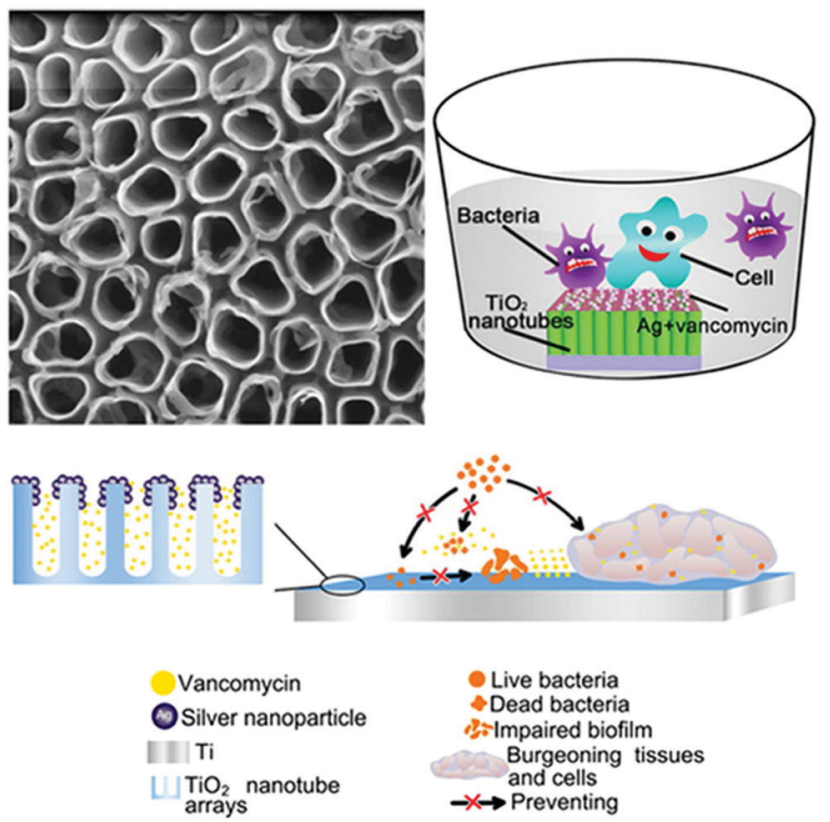

Fig. $4 \mathrm{~A} \mathrm{TiO}_{2}$ nanotube coating with embedded Ag NPs as an inorganic bactericide and vancomycin as an organic antibacterial agent, fabricated using $A O$ and PIII. ${ }^{67}$ Reprinted with permission. Copyright 2016, American Chemical Society.

The coating also showed antibacterial effects in a rat tibia osteomyelitis model. The mechanism of antibacterial activity was found to be not related to silver release. Wang et al. ${ }^{67}$ combined Ag NPs as an inorganic bactericide with vancomycin as an organic antibacterial agent to design a surface with both contact-killing and release-killing antimicrobial capabilities, as well as cell-assisting functions (Fig. 4). The Ag NPs were embedded in $\mathrm{TiO}_{2}$ nanotubes by anodic oxidation (AO) and PIII, and vancomycin was then incorporated into the nanotubes by vacuum extraction and lyophilisation. The hybrid surface showed antibacterial and anti-biofilm properties against mobile and attached methicillin-resistant $S$. aureus (MRSA) ST239 in vitro and in a rabbit model of periprosthetic joint infection, without appreciable silver ion release.

Wang et al. ${ }^{68}$ studied the antibacterial behaviour and the underlying mechanism of Ag-NPs embedded in a Ti substrate by PIII, and found that antibacterial function relied on the conductivity of the substrate. This study showed that electron transfer between Ag-NPs and Ti or between the Ag-NP doped Ti surface and bacteria could produce ROS and induce oxidative stress. Intracellular and extracellular oxidative stress can induce physiological changes in bacterial cells and lead to cell death. Cao et al. ${ }^{69}$ doped size-tunable Ag NPs into a plasma sprayed titanium oxide coating (TOC) by PIII. Large Ag NPs (5-25 $\mathrm{nm}$ ) were found to induce enhanced oxidation reactions on TOC compared to small NPs $(\sim 4 \mathrm{~nm})$, resulting in improved antibacterial activity of the TOC against $S$. aureus and E. coli. The mechanism by which extracellular electron transfer stimulates the bactericidal effect of Ag doped TOC in the dark was also investigated. The Ag NPs induced "bacterial charging" by storing extracellular electrons transferred from bacterial 
membranes, inducing valence-band hole $\left(\mathrm{h}^{+}\right)$accumulation and leading to oxidation reactions in the dark on the TOC surface. Zhao et al. ${ }^{70}$ co-doped $\mathrm{Mg}$ and $\mathrm{Ag}$ into Ti substrates by PIII, utilising the synergistic effect of multiple functional elements to improve both antibacterial and osteogenic properties. The $\mathrm{Mg} / \mathrm{Ag}$-doped group showed the best osteogenic activity compared to Mg-doped and Ag-doped groups. The mechanism is thought to be related to the galvanic effects between $\mathrm{Mg}$ and $\mathrm{Ag}$ NPs, which promoted $\mathrm{Mg}$ release but reduced silver release.

2.2.3 Laser cladding. Laser cladding is a coating technique whereby a laser beam heating source is used to melt the precursor powder, and the melted material is overlaid on the substrate to form a strong interfacial bond. Laser cladding has great advantages for the preparation of bioceramic coatings, giving them high bond strength together with good toughness and surface structure.

$\mathrm{CaO}-\mathrm{SiO}_{2}$ coatings on $\mathrm{Ti}$ implants prepared by laser cladding, containing different phases including $\mathrm{CaTiO}_{3}$, $\alpha-\mathrm{Ca}_{2}\left(\mathrm{SiO}_{4}\right), \mathrm{SiO}_{2}, \mathrm{TiO}_{2}$ and $\mathrm{CaO}$, can promote osteogenic activity in vivo after implantation. Li et al. ${ }^{71}$ added $\mathrm{Na}_{2} \mathrm{O}$ and $\mathrm{ZnO}$ into the $\mathrm{CaO}-\mathrm{SiO}_{2}$ precursor to prepare bioceramic coatings by laser cladding on a Ti substrate (Fig. 5). At temperatures above $1200{ }^{\circ} \mathrm{C}, \mathrm{CaTiO}_{3}$ was easily formed in the $\mathrm{CaO}-\mathrm{SiO}_{2}$ coating in comparison to $\mathrm{CaSiO}_{3}$. The effect of $\mathrm{Na}_{2} \mathrm{O}$ and $\mathrm{ZnO}$ on the microstructure and properties of $\mathrm{CaO}-\mathrm{SiO}_{2}$ coatings was studied. The addition of $\mathrm{Na}_{2} \mathrm{O}$ was found to have little effect on the coating, but $\mathrm{ZnO}$ refined the microstructure of the coating and reduced its wear resistance and average hardness. The same researchers also explored the use of $\mathrm{MgO}$ to improve $\mathrm{CaO}-\mathrm{SiO}_{2}$ coatings. $^{72}$ The $\mathrm{CaO}-\mathrm{SiO} 2-\mathrm{MgO}$ coating system produced by laser cladding showed a refined surface microstructure, and slightly lower average hardness compared with the $\mathrm{CaO}-\mathrm{SiO}_{2}$ control. An increase in $\mathrm{MgO}$ content led to a decrease in wear resistance. In vitro and in vivo tests indicated good biocompatibility of the coating, which did not cause haemolysis reactions or toxicity to cells and living animals. The modified $\mathrm{CaO}-\mathrm{SiO}_{2}$ coatings in these studies were shown to induce apatite formation, but no further in vitro or in vivo experiments were performed to test their ability in promoting osseointegration.

\subsection{Chemical modification methods}

Chemical modification methods usually involve a violent chemical reaction, which for a Ti substrate occurs at the interface of the metal surface and the imposed media (solution or gas phase). The reaction is often accompanied by luminescence, heating, redox reaction, and so on. Chemical modification methods including sandblasting and acid etching, thermal oxidation, hydrothermal treatment, anodic oxidation, and micro arc oxidation have been widely employed for preparing surfaces with special topographical structures and/or complex compositions. ${ }^{37}$

2.3.1 Sandblasting and acid etching (SLA). SLA is a twostep surface modification method, whereby the first step is to

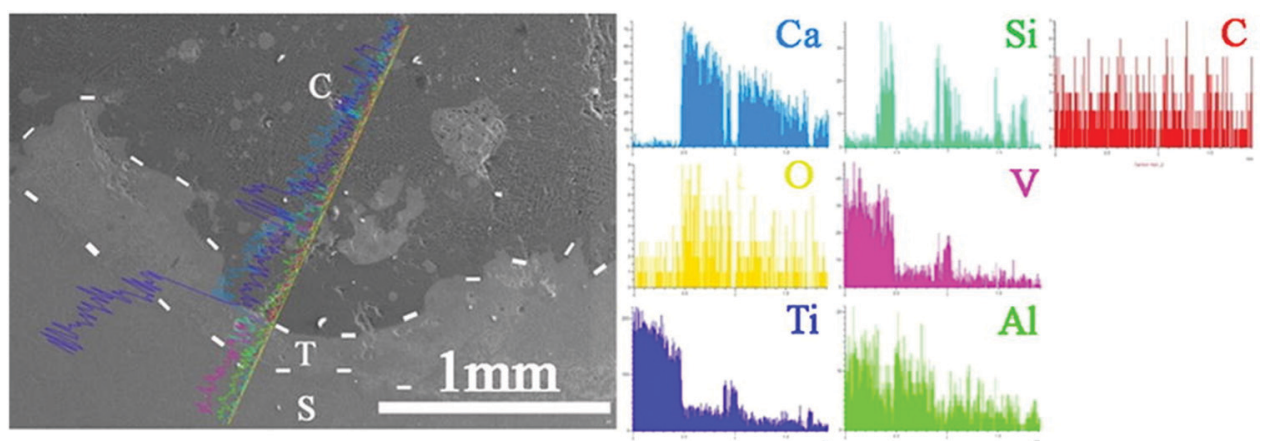

C: ceramic layer, T: transition layer; $\mathrm{S}$ : substrate
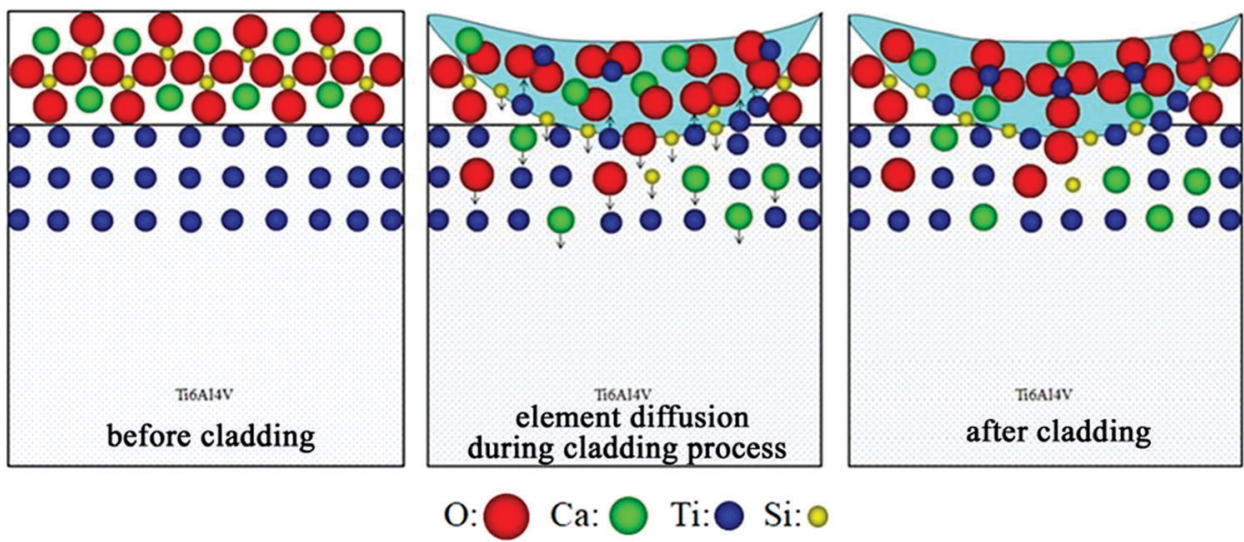

Fig. 5 Schematic illustration of the cross-sectional morphology and line analyses of $\mathrm{CaO}-\mathrm{SiO}_{2}$ coatings formed by laser cladding, and the mechanism of surface formation. ${ }^{71}$ Reprinted with permission. Copyright 2021, Elsevier. 
obtain a primary rough structure of $10-100 \mu \mathrm{m}$ by sandblasting, using a high-speed jet beam formed by compressed air to spray different sized particles onto the implant surface. Common materials used for sandblasting include quartz sand, HA, alumina, $\mathrm{TiO}_{2}$, and iron oxide particles. The second step is to obtain a secondary rough structure of $1-3 \mu \mathrm{m}$ by acid etching the $\mathrm{Ti}$ implant surface at high temperature using acids such as $\mathrm{HCl}, \mathrm{H}_{2} \mathrm{SO}_{4}, \mathrm{H}_{3} \mathrm{PO}_{4}, \mathrm{HNO}_{3}$, or a mixture of these. SLA is classified as chemical modification since it mainly relies on acid etching to regulate the surface micro-morphology.

Raines et al. $^{73}$ prepared SLA and modified SLA (modSLA; SLA without exposure to air to retain high surface free energy) surfaces, which were cultured with primary human osteoblasts, MG63 cells, and MG63 cells silenced for $\alpha 2$ integrin. Analysis of secreted levels of vascular endothelial growth factor-A (VEGF-A), basic fibroblast growth factor (FGF-2), epidermal growth factor (EGF), and angiopoietin-1 (Ang-1) by these cells indicated that the secretion of angiogenic growth factors by osteoblastic cells was modulated by $\mathrm{Ti}$ surface micro-topography and surface energy, which was at least partially mediated by $\alpha_{2} \beta_{1}$ integrin signalling. Boyan et al. ${ }^{74}$ used SLA or plasma spraying to produce microrough $\mathrm{Ti}$ surfaces with an average roughness of 4-7 $\mu \mathrm{m}$, and demonstrated through an in vitro model that microscale roughness could create a microenvironment for osteoblasts to form new bone. Gittens et al. ${ }^{75}$ combined SLA with thermal oxidation to prepare surfaces with micro-/ sub-micro-scale roughness and nanoscale features. The micro-/ sub-micro-scale surface roughness was found to facilitate osteoblast adhesion, while the nanoscale features promoted osteoblast proliferation and differentiation. Interestingly, greatly enhanced osteoblast differentiation was seen on surfaces with both microscale roughness and a high density of nanoscale features, indicating a possible synergistic effect due to mimicking the layered complexity of bone. On sample surfaces without microscale roughness, the nanoscale features alone did not induce appreciable increases in osteoblast differentiation markers. In another study, Zhang et al. ${ }^{76}$ modified Ti surfaces using SLA followed by further alkali or hydrogen peroxide treatment, and then heat treatment. Both types of surfaces promoted the osteogenic activity of MC3T3-E1 cells, and also showed good osseointegration in a canine mandibular defect model.

SLA-treated Ti surfaces have also been studied in the context of certain diseases or conditions. For instance, Lee et al. ${ }^{36}$ produced hydrophilic nanostructured Ti surfaces by modifying with SLA and then storing in the absence of air to induce spontaneous formation of surface features (Fig. 6). This surface was found to promote osseous healing under type II diabetic conditions. When implanted into bone defects in a diabetic rat model, Ti implants with hydrophilic nanostructured surfaces promoted osteogenesis, together with the expression of antiinflammatory proteins including AnxA1, S100-A8 and S100-A9. Surfaces cultured with macrophages in vitro reduced proinflammatory cytokine secretion and promoted M2 phenotype differentiation. As a strategy for combating infection, Liu et $a l .{ }^{77}$ prepared a Ti-Cu alloy and modified the surface by SLA treatment. Compared to a mechanically polished surface, the SLA-treated surface was found to release more $\mathrm{Cu}$ ions, possess better antibacterial properties against $S$. aureus, and improve the osteogenic activity of MC3T3-E1 cells.

2.3.2 Thermal oxidation. Thermal oxidation is a relatively simple, convenient, and cost effective method that modifies the

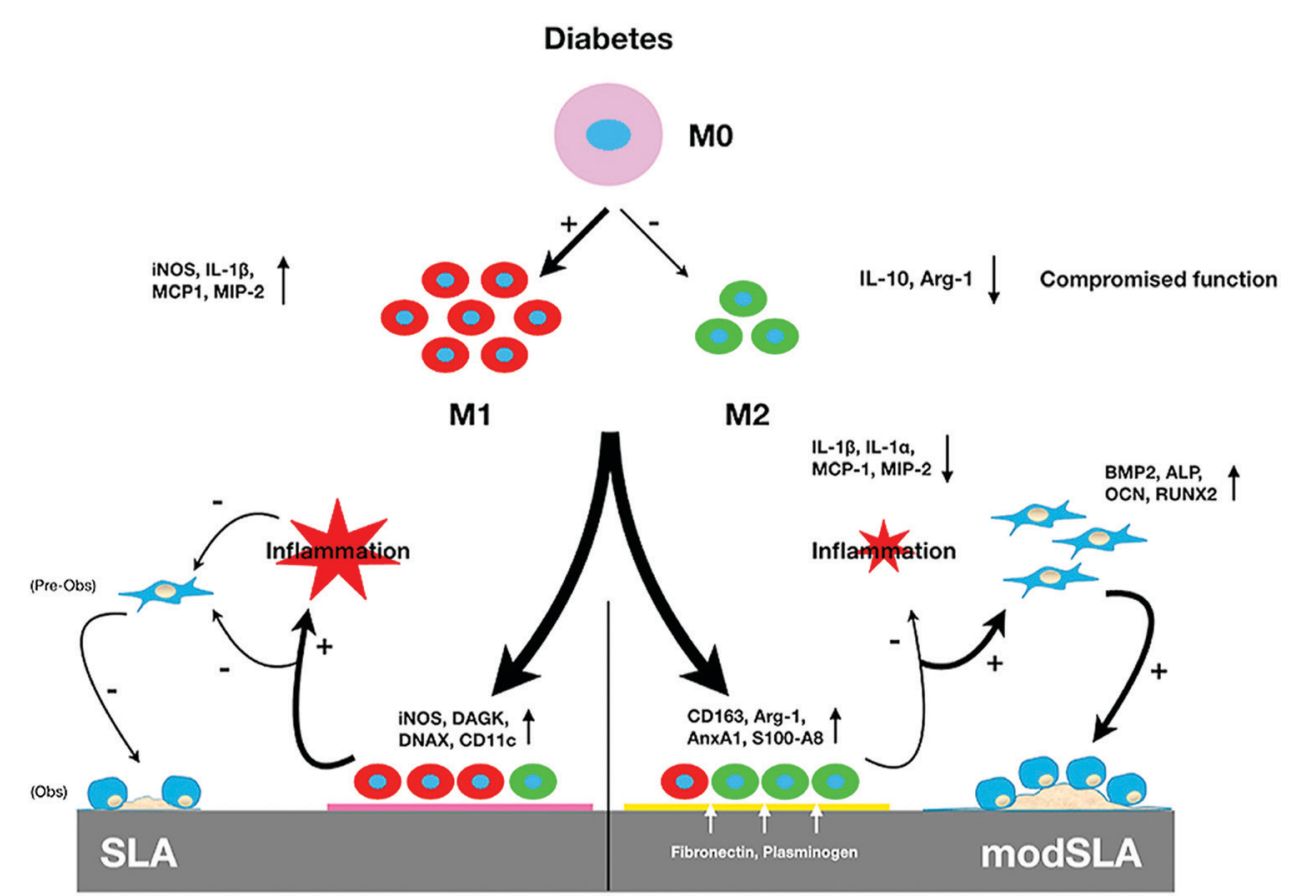

Fig. 6 Schematic illustration of the mechanism by which modified hydrophilic nanostructured surfaces produced using SLA can modulate inflammation and promote osseous healing under type II diabetic conditions. ${ }^{36}$ Reprinted with permission. Copyright 2021, Elsevier. 
natural inert oxide film on Ti surfaces. The main parameters regulating the oxidation process are temperature and time. In general, thermal oxidation treatment of titanium oxide layers requires a moderate temperature and time to produce good mechanical and chemical properties. At high temperatures (above $800{ }^{\circ} \mathrm{C}$ ) and long oxidation times, oxide debonding occurs on the implant surface, while at low temperatures and short oxidation times, the oxide layer cannot reach the required thickness to be useful in biomedical applications.

Scarano et $a l^{78}$ conducted oxidation treatment on $\mathrm{Ti}$ implants at $802{ }^{\circ} \mathrm{C}$ for $1 \mathrm{~min}$ in the air, where the temperature was chosen as it caused an increase in crystalline anatase, and the short time was chosen to improve the mechanical properties. Compared to control implants without oxidation treatment, the treated implants showed better bioactivity and bone-implant contact in a rabbit femoral defect model. Wang et al. ${ }^{79}$ designed a thermal oxidation method to produce micro-/nano-scale features on the modified $\mathrm{Ti}$ surface. The $\mathrm{Ti}$ substrate was thermally treated at $450{ }^{\circ} \mathrm{C}$ for 6 hours, which enhanced the osteogenic differentiation of rat BMSCs and promoted in vivo osseointegration in the rabbit femur. Longhitano et al. ${ }^{80,81}$ tested the effects of different thermal oxidation temperatures (from 650 to $1050{ }^{\circ} \mathrm{C}$ ) on Ti6Al4V samples made by additive manufacturing (Fig. 7A). The main differences in surface microstructure between different heating temperatures were found to be the nucleation and growth of $\alpha$ and $\beta$ phases. Jenkins et al. ${ }^{82}$ prepared $\mathrm{TiO}_{2}$ nanopillars on Ti6Al4V samples through a thermal oxidation reaction at $850{ }^{\circ} \mathrm{C}$ in acetone vapour. Interestingly, contrary to previous studies speculating that the antimicrobial properties of a nanopillar surface morphology are based on mechanical damage, this study showed that nanopillars caused deformation and penetration of the cell envelope in Grampositive and Gram-negative bacteria (Fig. 7B). They could inhibit bacterial cell division and trigger production of ROS, but did not rupture or lyse the bacteria. These results suggested that the antibacterial activity of Ti surface nanopillars might be mediated by oxidative stress rather than inducing bacterial lysis and death.

Heat treatment can be used as a pre- or post-modification method for other technologies to improve the effect of surface modification. For instance, Gu et al. ${ }^{83}$ used a thermal treatment of $160{ }^{\circ} \mathrm{C}$ for 2 hours, which enhanced the adhesive bond strength of graphene on a Ti substrate without affecting the
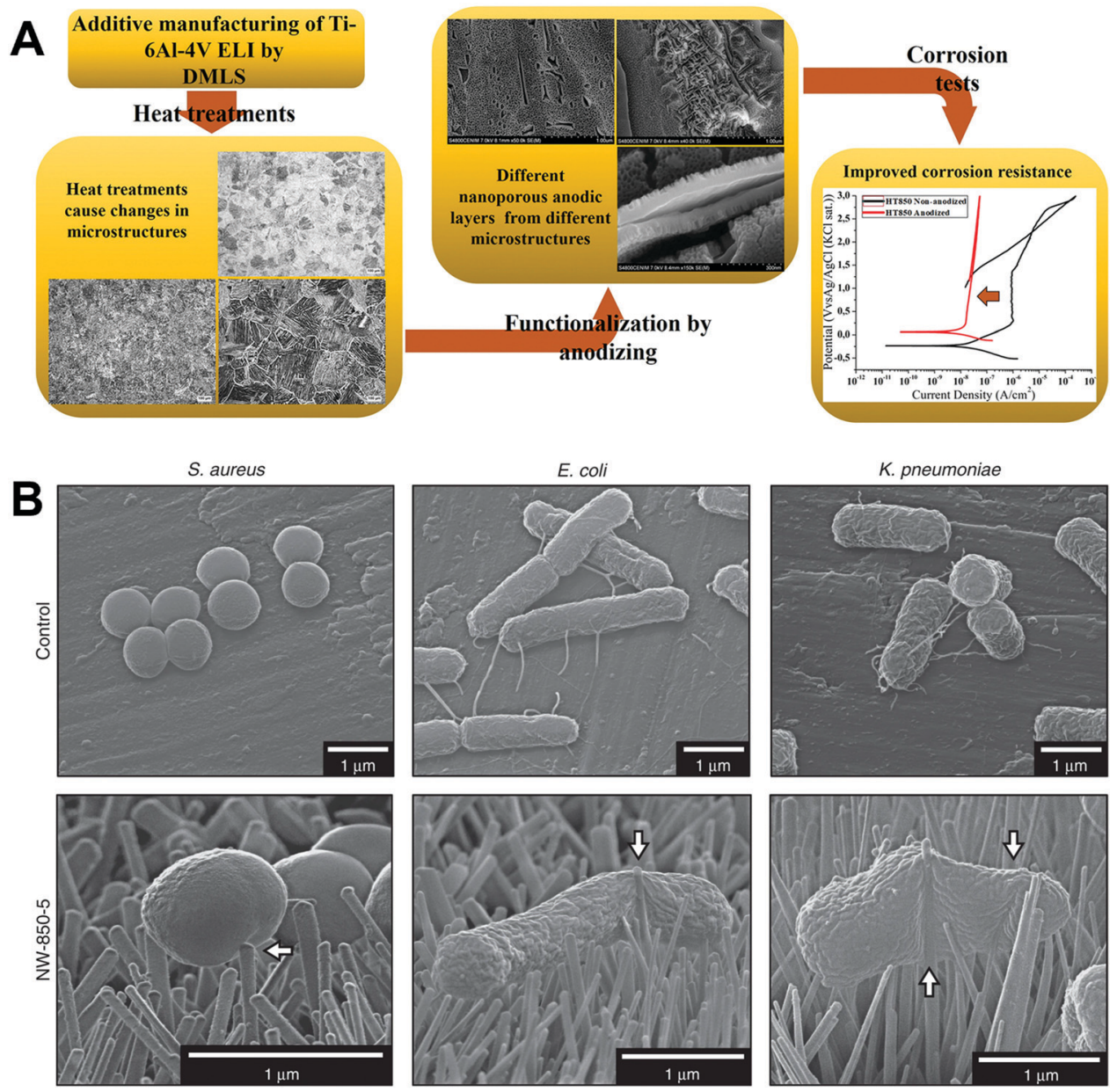

Fig. 7 (A) Use of thermal oxidation to fabricate surface microstructures on Ti6Al4V samples made by additive manufacturing (direct metal laser sintering, DMLS). ${ }^{81}$ (B) Morphology of different bacteria on $\mathrm{TiO}_{2}$ nanopillars compared to flat Ti6Al4V surfaces. ${ }^{82}$ White arrows = nanopillar-induced envelope deformation. Reprinted with permission. (A) Copyright 2018, Elsevier; (B) Copyright 2020, Springer Nature. 
favourable ability of the graphene coating to induce osteogenic activity in human bone marrow and adipose tissue derived stem cells. To improve the stability of plasma sprayed HA coatings, Bose et al. ${ }^{84}$ applied a thermal treatment on sprayed Ti6Al4V samples at $800{ }^{\circ} \mathrm{C}$ for $10 \mathrm{~min}$. The treatment increased coating crystallinity from 64 to $75 \%$ and adhesion strength from 26 to $31 \mathrm{MPa}$, while decreasing the HA dissolution rate. This method could be useful for reducing the chance of HA coating delamination from the metal implant due to poor interfacial bonding.

2.3.3 Hydrothermal treatment. Hydrothermal treatment is a widely used method for modifying $\mathrm{Ti}$ and its alloys and involves a chemical reaction in water in a sealed pressure vessel, such that the reaction proceeds under high temperature and high pressure conditions. The hydrothermal reaction conditions covered in this section are summarised in Table 1 . After hydrothermal treatment, the Ti surface can be modified by changing the nanotopography, wettability, and even composition through element doping.

A number of studies have used hydrothermal treatment to dope $\mathrm{Sr}$ in orthopaedic implant coatings, since $\mathrm{Sr}$ can promote bone formation and inhibit bone resorption. ${ }^{85-87}$ Dang et al. ${ }^{85}$ used electrochemical anodisation and hydrothermal treatment to produce Sr-doped Ti nanotubes on Ti implant surfaces. The surface prepared using an anodisation voltage of $10 \mathrm{~V}$ and a hydrothermal treatment time of 3 hours showed the best ability to support in vivo bone formation. In an orthotopic rat model, implants with this surface achieved the best osseointegration and bone-implant contact ratio compared to other surfaces. The ability of the surface to induce rapid in vivo bone formation was thought to be due to the synergistic effect of surface micro-/ nano-morphology and element release from the coating. Zhang et al. ${ }^{86}$ synthesised a Ti surface with $\mathrm{Sr}$ and $\mathrm{Ca}$ co-doped $\mathrm{TiO}_{2}$ nanotubes (M-SrCaNT) by applying a modified anodisation and hydrothermal treatment. In this study, half of the $\mathrm{Sr}$ in Sr-incorporated $\mathrm{TiO}_{2}$ nanotubes (M-SrNT) was replaced by $\mathrm{Ca}$ to obtain M-SrCaNT, which did not change the surface micro-/ nano-structure. M-SrCaNT showed better ability to promote osteogenic activities (gene expression, extracellular matrix synthesis and mineralisation) in MC3T3-E1 cells than M-SrNT and unmodified $\mathrm{TiO}_{2}$ nanotubes. However, in vivo experiments were not performed to verify the ability of the coating to support osseointegration. Geng et al. ${ }^{87}$ prepared a snailinspired Sr-doped HA coating on $\mathrm{Ti}$ by electrochemical corrosion, ultrasonic treatment, and hydrothermal treatment. In vitro and in vivo experiments showed that this coating effectively promoted the proliferation and differentiation of osteoblasts while inhibiting the formation of osteoclasts, as shown through the expression of relevant genes (ITG $\alpha 5 \beta 1$, Col-I, OCN, RANKL). In a rabbit model, the biomimetically structured surface with pore spaces was beneficial for bone formation and allowed implant-bone mechanical interlocking. The bioactive HA composition was thought to promote bone formation, while the doped $\mathrm{Sr}$ ions inhibited bone resorption.

Phosphate has gained an increasing number of biomedical applications in recent years, and its formation on Ti surfaces by hydrothermal treatment has been explored. Titanium phosphate (TiP) coatings with a variety of morphologies have been prepared and studied. For example, Jiang et al. ${ }^{88}$ produced three hybrid coatings containing $\mathrm{TiP}$ and $\mathrm{TiO}_{2}$, named micro/ nanoclump $\mathrm{Ti}$ (P-C-Ti), micro/nanograss $\mathrm{Ti}(\mathrm{P}-\mathrm{G}-\mathrm{Ti})$, and micro/nanorod Ti (P-R-Ti) (Fig. 8A). The preparation method mainly involved a reaction between $\mathrm{Ti}, \mathrm{H}_{2} \mathrm{O}_{2}$, and $\mathrm{H}_{3} \mathrm{PO}_{4} \cdot \mathrm{Ti}^{4+}$ ions were produced as shown in eqn (1) and (2):

$$
\begin{gathered}
\mathrm{H}_{2} \mathrm{O}_{2}+2 \mathrm{H}^{+}+2 \mathrm{e}^{-} \rightarrow 2 \mathrm{H}_{2} \mathrm{O} \\
\mathrm{Ti}+2 \mathrm{H}_{2} \mathrm{O}_{2}+4 \mathrm{H}^{+} \rightarrow \mathrm{Ti}^{4+}+4 \mathrm{e}^{-}
\end{gathered}
$$

Further reaction could form $\mathrm{Ti}\left(\mathrm{O}_{2}\right)(\mathrm{OH})_{n-2}{ }^{(4-n)+}(\mathrm{pH}<1)$ or $\mathrm{Ti}_{2} \mathrm{O}_{5}(\mathrm{OH})_{x}^{2-\mathrm{x}}(\mathrm{pH}>1, x=1-6)$. Then, the deposition of

Table 1 Summary of hydrothermal reaction conditions

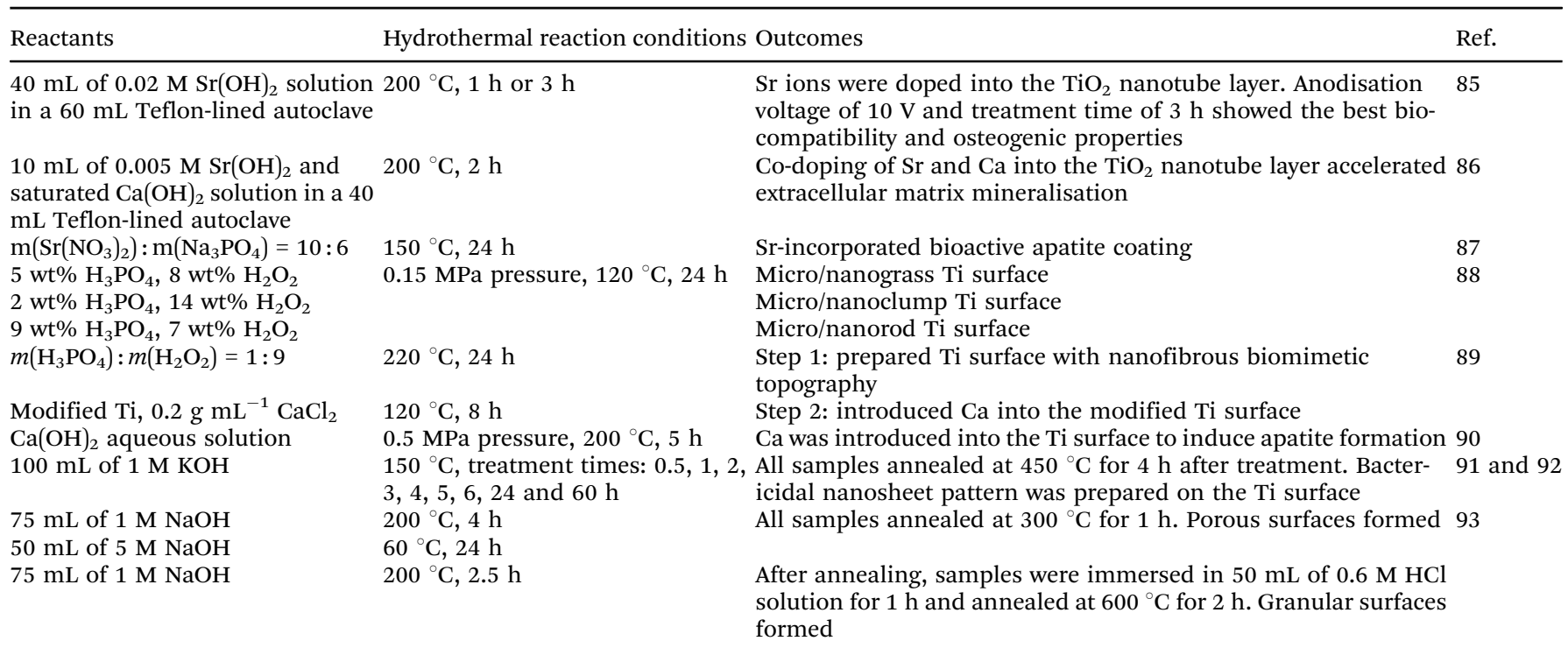



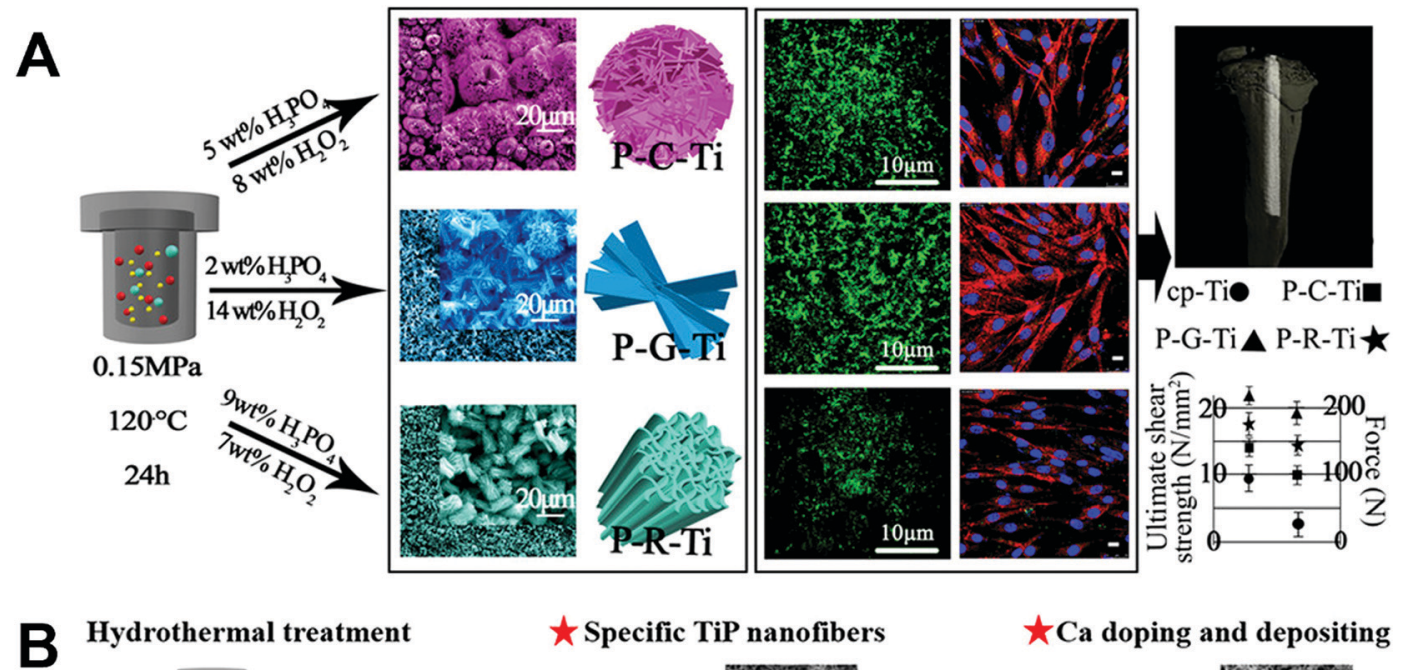

Hydrothermal treatment
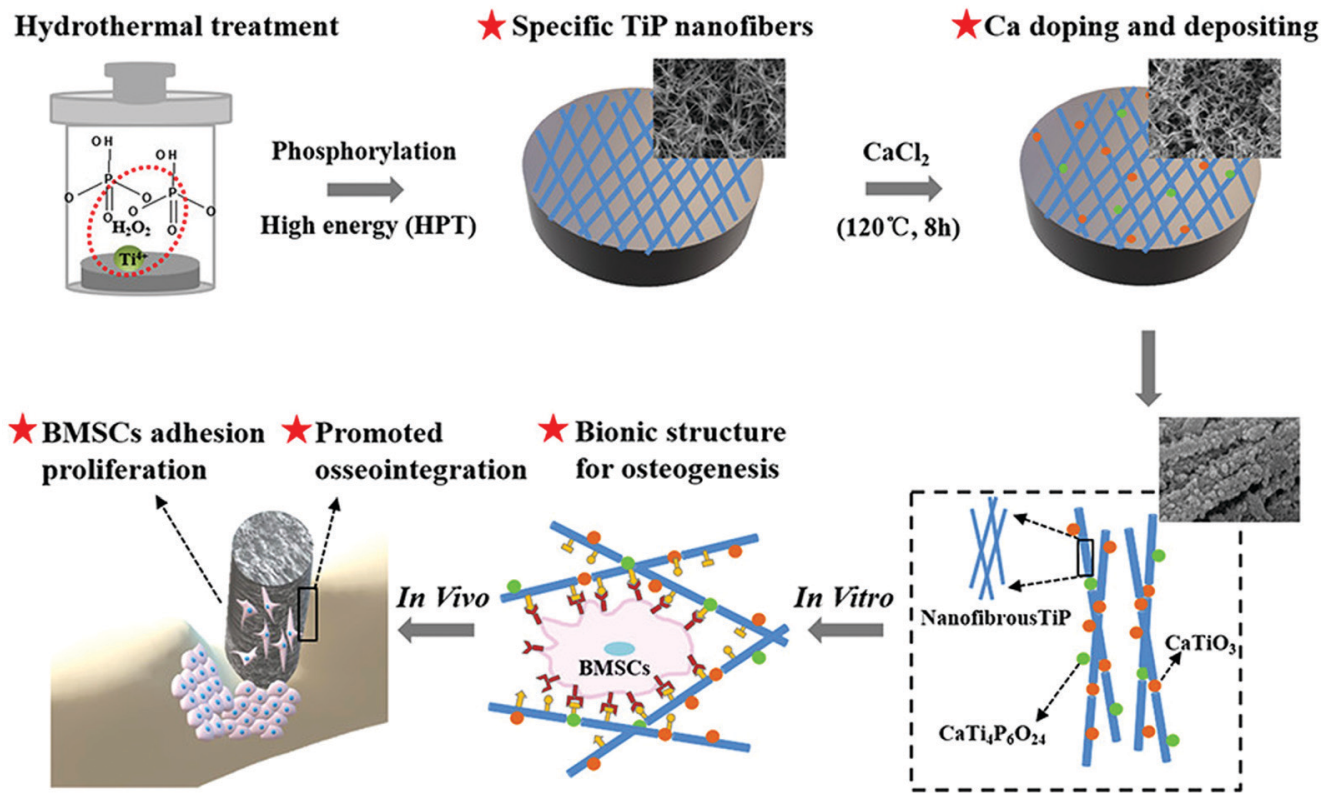

Fig. 8 Use of hydrothermal treatment on Ti implants to fabricate (A) three unique micro-/nano-structured surface coatings involving TiP, ${ }^{88}$ and (B) bioinspired nanofibrous Ca-doped TiP coating. ${ }^{89}$ Reprinted with permission. Copyright 2018 \& 2020, American Chemical Society.

amorphous or low crystallinity TiP was produced by a reaction between the oxidised substrate and phosphate or hydrogen phosphate ions. During the treatment process, $\mathrm{H}_{3} \mathrm{PO}_{4} / \mathrm{H}_{2} \mathrm{O}_{2}$ concentrations were adjusted to control the coating morphology and composition (see Table 1). In vitro and in vivo experiments indicated that $\mathrm{P}-\mathrm{G}-\mathrm{Ti}$ allowed the best protein adsorption and rat BMSC viability, adhesion, and differentiation, as well as produced the highest tissue-implant interfacial bonding strength in rat tibia.

Cai et $a .^{89}$ fabricated a bioinspired nanofibrous Ca-doped TiP coating on Ti by a two-step hydrothermal treatment method (Fig. 8B). In step one, the Ti sample was immersed in an aqueous solution $\left(m\left(\mathrm{H}_{3} \mathrm{PO}_{4}\right): m\left(\mathrm{H}_{2} \mathrm{O}_{2}\right)=1: 9\right)$ at $220{ }^{\circ} \mathrm{C}$ for 24 hours to form TiP. In step two, $0.2 \mathrm{~g} \mathrm{~mL}^{-1} \mathrm{CaCl}_{2}$ solutions were applied to dope $\mathrm{Ca}$ into the Ti surface at $120{ }^{\circ} \mathrm{C}$ for $8 \mathrm{~h}$. The main reaction process is shown in eqn (3), (4) and (5):

$$
\mathrm{CaCl}_{2} \rightarrow \mathrm{Ca}^{2+}+2 \mathrm{Cl}^{-}
$$

$$
\begin{gathered}
\mathrm{Ca}^{2+}+\mathrm{H}_{2} \mathrm{O}_{2}+\mathrm{TiO}_{2} \rightarrow \mathrm{CaTiO}_{3}+\mathrm{H}_{2} \mathrm{O} \\
\mathrm{Ca}^{2+}+2 \mathrm{Ti}\left(\mathrm{HPO}_{4}\right)_{2}+\mathrm{TiH}_{2} \mathrm{P}_{2} \mathrm{O}_{8} \rightarrow \mathrm{CaTiO}_{3} \mathrm{P}_{6} \mathrm{O}_{24}+\mathrm{H}_{2} \mathrm{O}
\end{gathered}
$$

In vitro tests using rat BMSCs and in vivo assessment in the rat tibia showed an improved ability of the Ca-doped TiP coating to encourage osteogenic behaviour and induce osseointegration in the early implantation state together with higher interfacial bonding strength, compared to the control TiP coating. In another coating containing $\mathrm{Ca}$, Ansar et al. ${ }^{90}$ introduced $\mathrm{Ca}$ into the $\mathrm{Ti}$ surface using $\mathrm{Ca}(\mathrm{OH})_{2}$ through a one-step hydrothermal treatment method. $\mathrm{CaO}$ and $\mathrm{CaTiO}_{3}$ were detected in the coating, where the reaction for $\mathrm{CaTiO}_{3}$ formation is shown in eqn (6) and (7):

$$
\begin{gathered}
\mathrm{Ca}(\mathrm{OH})_{2}(\mathrm{~s}) \rightarrow \mathrm{Ca}^{2+}+2 \mathrm{OH}^{-} \\
\mathrm{Ca}^{2+}+\mathrm{Ti}(\mathrm{OH}) \rightarrow \mathrm{CaTiO}_{3}(\mathrm{~s})+2 \mathrm{H}^{+}+\mathrm{H}_{2} \mathrm{O}
\end{gathered}
$$

This is a simple, quick, and low-cost method for preparing a bioactive coating on $\mathrm{Ti}$ that has the ability to 
induce apatite formation, but the coating has no special morphology.

The optimisation of antimicrobial properties is crucial for implant surface modification, and a number of studies have used hydrothermal treatment for this purpose. Wandiyanto et $a l .{ }^{91}$ prepared a Ti surface coating with sharp-edged (about $10 \mathrm{~nm}) \mathrm{TiO}_{2}$ nanosheets to confer bactericidal properties. The nanosheet surface with different edge lengths was made by adjusting the hydrothermal treatment time, from 0.5 to 60 hours. The surface produced by 6 hours of treatment showed the best antibacterial performance, eliminating $90 \pm 9 \%$ of $S$. aureus and $\sim 100 \%$ of $P$. aeruginosa cells contacting the coating. However, biocompatibility and bone integration experiments were not performed in this study. Following on from this, Clainche et al. ${ }^{92}$ tested two types of antibacterial coatings that combined both osteogenic and antibiotic activity, comparing hydrothermal treatment with plasma etching as the fabrication methods. The coating produced by hydrothermal treatment has been described by Wandiyanto et al. ${ }^{91}$ to contain sharp nanosheet protrusions to kill bacteria by cutting the cell membrane, while the other coating produced by plasma etching has been described by Linklater et al. ${ }^{94}$ to contain a microscale two-layer hierarchical topography to both reduce bacterial attachment and rupture bacteria that contact the surface. In vitro experiments showed that both coatings could selectively destroy bacterial cells, since they promoted the adhesion and differentiation of human adipose-derived stem cells (ASCs) and supported their osteogenesis. Further in vivo testing is necessary to confirm these observations.

Thrombosis is one of the reasons for bone implant failure. To address this problem, Manivasagam and Popat ${ }^{93}$ prepared Ti and Ti6Al4V surfaces with different morphologies using hydrothermal treatment, by adjusting the solution concentration, reaction temperature, and treatment time. A porous surface prepared on Ti was found to be the most haemocompatible compared to all other surfaces, which was produced by immersing the sample in $50 \mathrm{~mL}$ of $5 \mathrm{M} \mathrm{NaOH}$ solution, hydrothermal treatment at $60{ }^{\circ} \mathrm{C}$ for 24 hours, and annealing at $300{ }^{\circ} \mathrm{C}$ for 1 hour. The porous surface could modulate fibrinogen adsorption, cell adhesion, platelet activation, and whole blood clotting in vitro. This may lead to increased blood compatibility, reduced thrombosis and improved osteogenesis in vivo, although animal experiments were not performed in this study.

Microwave hydrothermal treatment (MWHT) is a method for producing nanoscale structures on alloy surfaces, where the reaction rate of organic and inorganic synthesis in hydrothermal treatment is increased by microwave heating. Compared with traditional hydrothermal treatment technology, MWHT is characterised by low temperature and high speed. Cheng et $a{ }^{95}{ }^{95}$ examined several MWHT surfaces prepared on two substrates (microrough and smooth Ti surfaces) in three solutions (distilled water, aqueous $\mathrm{H}_{2} \mathrm{O}_{2}$ solutions (1-2.5 M), and aqueous $\mathrm{NH}_{4} \mathrm{OH}$ solutions (1-2.5 M)) at $200{ }^{\circ} \mathrm{C}$ for 1 hour. Microrough Ti surfaces subjected to MWHT with distilled water or $\mathrm{NH}_{4} \mathrm{OH}$ solutions produced anatase titania nanoprotuberances with average diameters of 23-60 nm, while MWHT with $\mathrm{H}_{2} \mathrm{O}_{2}$ solutions produced rutile-bearing titania nano-protuberances with average diameters of 22-51 $\mathrm{nm}$. Interestingly, while these nanoscale modifications improved the hydrophilicity of the microrough $\mathrm{Ti}$ surface, they had no significant effects on osteogenic differentiation by MG63 cells and normal human osteoblasts compared to microrough $\mathrm{Ti}$ controls not treated by MWHT.

2.3.4 Anodic oxidation (AO). AO is a commonly used surface modification method that can form oxide films on the surface of metals through a discharge oxidation process. As indicated by the technical name 'anodic oxidation', the metal to be oxidised is fixed on the anode of the electrolytic cell. By applying a specific voltage, the positive and negative ions in the electrolyte diffuse to the cathode and anode under the action of the electric field, and redox reactions occur. The oxide film on the metal surface undergoes a repeated alternating process of formation and disappearance, leading to the final formation of a special surface morphology - uniform micro/nanoscale pore or tube arrays. As shown in Table 2, changing operating

Table 2 Summary of anodic oxidation conditions

\begin{tabular}{|c|c|c|c|c|c|c|c|}
\hline Electrolyte composition & $\begin{array}{l}\text { Work } \\
\text { potential (V) }\end{array}$ & $\begin{array}{l}\text { Time } \\
\text { (min) }\end{array}$ & $\begin{array}{l}\text { Thickness } \\
(\mu \mathrm{m})\end{array}$ & $\begin{array}{l}\text { Average } \\
\text { roughness }(\mathrm{nm})\end{array}$ & $\begin{array}{l}\text { Water contact } \\
\text { angle }\left(^{\circ}\right)\end{array}$ & $\begin{array}{l}\text { Nanotube inner } \\
\text { diameter }(\mathrm{nm})\end{array}$ & Ref. \\
\hline 0.5 wt $\% \mathrm{NH}_{4} \mathrm{~F}, 5$ vol\% $\mathrm{H}_{2} \mathrm{O}$, ethylene glycol (EG) & $\begin{array}{l}0 \\
20 \\
40 \\
60 \\
80 \\
100\end{array}$ & 60 & $\begin{array}{l}0 \\
0.21 \\
1.90 \\
1.81 \\
1.81 \\
1.92\end{array}$ & $\begin{array}{l}10.67 \\
29.36 \\
38.75 \\
56.35 \\
132.11 \\
111.97\end{array}$ & $\begin{array}{r}79.2 \pm 0.2 \\
122.0 \pm 0.1 \\
142.4 \pm 0.1 \\
130.7 \pm 0.1 \\
142.1 \pm 0.1 \\
103.8 \pm 1.0\end{array}$ & $\begin{array}{l}- \\
- \\
- \\
-\end{array}$ & 100 \\
\hline $1 \mathrm{M}$ lactic acid, $0.1 \mathrm{M} \mathrm{NH}_{4} \mathrm{~F}, 1.5 \mathrm{wt} \% \mathrm{H}_{2} \mathrm{O}$, EG & 160 & 15 & 79 & - & - & - & 101 \\
\hline 0.5 wt $\% \mathrm{NH}_{4} \mathrm{~F}, 1 \mathrm{wt} \% \mathrm{H}_{2} \mathrm{O}, \mathrm{EG}$ & 60 & $\begin{array}{l}10 \\
20 \\
30 \\
40 \\
50 \\
60\end{array}$ & $1.30 \pm 0.09$ & $\begin{array}{l}- \\
- \\
- \\
-\end{array}$ & $\begin{array}{l}44.6 \pm 1 \\
43.1 \pm 1 \\
61.8 \pm 1 \\
40.8 \pm 1 \\
29.4 \pm 1 \\
15.9 \pm 1\end{array}$ & $\begin{array}{l}100 \\
75 \\
65 \\
70 \\
75 \\
50\end{array}$ & 102 \\
\hline 0.25 wt $\% \mathrm{NH}_{4} \mathrm{~F}, 2$ wt $\% \mathrm{H}_{2} \mathrm{O}, \mathrm{EG}$ & 15 & 60 & - & $15.62 \pm 1.85$ & $39.2 \pm 4.4$ & $40-50$ & 103 \\
\hline 0.5 wt $\% \mathrm{NH}_{4} \mathrm{~F}, 5$ vol $\% \mathrm{CH}_{3} \mathrm{OH}, 5$ vol $\% \mathrm{H}_{2} \mathrm{O}, \mathrm{EG}$ & $\begin{array}{l}10 \\
40\end{array}$ & $\begin{array}{l}60 \\
40\end{array}$ & $\begin{array}{l}0.045 \\
0.04\end{array}$ & - & - & $\begin{array}{l}30 \\
80\end{array}$ & 85 \\
\hline
\end{tabular}


parameters such as work potential, treatment time, and electrolyte composition can alter the properties of the metal oxides produced and hence control the results of surface modification, including roughness, topography, hydrophobicity, corrosion resistance, and other properties of the metal substrate. Compared to other chemical surface modification methods, the AO technique is relatively simple and low in cost. It has been widely used to prepare surfaces with $\mathrm{TiO}_{2}$ nanotubes, particularly the so-called high aspect ratio (HAR) nanotube coatings with desired $50-300 \mu \mathrm{m}$ thickness. ${ }^{96}$ The necessary conditions for producing nanotube arrays on Ti surfaces are the presence of both $\mathrm{F}^{-}$ions and low $\mathrm{pH}$, causing changes in nanoscale morphology as a function of anodisation time from non-porous oxide, to pit formation, pore growth, and finally nanotube arrays. ${ }^{97}$ Nanoscale surface morphology of implants is known to be a significant driver for bone ingrowth, as seen in early studies where osteoblasts showed increased adhesion and higher amounts of calcium-containing mineral deposition on nanophase metallic surfaces. ${ }^{98,99}$ In the natural state, the $\mathrm{TiO}_{2}$ formed on the surface of Ti implants is bioinert, while after AO treatment this evolves into bioactive rutile and anatase phases.

In 1999, Zwilling et al. ${ }^{104}$ first prepared a layer of $\mathrm{TiO}_{2}$ nanotubes on a $\mathrm{Ti}$ substrate in chromic acid electrolytes containing hydrogen fluoride at low voltage, which was approximately $500 \mathrm{~nm}$ thick. At the time, the prepared $\mathrm{TiO}_{2}$ nanotubes did not have a tightly organised structure and the sidewall was not uniform. Moreover, it was found that the thickness of the $\mathrm{TiO}_{2}$ nanotube layer did not increase with treatment time, possibly due to an equilibrium state of oxide growth and chemical dissolution. Since then, the use of AO to prepare $\mathrm{TiO}_{2}$ nanotubes has attracted extensive attention. ${ }^{29,104}$ Durdu et $a{ }^{100}$ recently prepared a well-organised hydrophobic $\mathrm{TiO}_{2}$ nanotube coating with high crystallinity as well as homogeneous morphology and elemental distribution, by combining the AO method at different voltages with post-heat treatment. The post-heat treatment was found to not affect the morphological changes in the coating. Ti samples with the $\mathrm{TiO}_{2}$ nanotube coated surface produced at $20 \mathrm{~V}$ showed better mechanical properties when compared with uncoated controls and other coatings. Increases in the voltage value resulted in higher coating hydrophilicity, as well as changes in morphology from well-ordered to random organisation of nanotubes. In a study by Alijani et al., ${ }^{101}$ an accurate optimisation of AO conditions was first successfully realised at room temperature to produce HAR nanotubes. The surface could be produced in a short time without the traditional high temperature requirement, by adding lactic acid in the electrolyte to prevent dielectric breakdown and enable anodisation at higher potentials. This method produced a high growth rate for the nanotube layer of up to $5.266 \mu \mathrm{m} \mathrm{min}^{-1}$. Torres-Avila et al. ${ }^{102}$ tested the impact of different oxidation times (10 to $60 \mathrm{~min}$ ) on $\mathrm{TiO}_{2}$ nanotubes produced on Ti6Al4V using AO at a constant work potential of $60 \mathrm{~V}$. The oxidation time was found to significantly affect the inner diameter of nanotubes, which was directly correlated with cell proliferation. Nanotubes with an inner diameter of $60 \mathrm{~nm}$ allowed the highest proliferation of a human osteoblast cell line.

AO can be applied to modulate surface charge, which is important since electrical stimulation can promote osteogenesis through biological interactions, such as with naturally charged biomolecules. This has been explored for ceramic biomaterials such as hydroxyapatite. ${ }^{105}$ A convergence of surface chemistry, surface charge, topography, and hydrophilicity is necessary for designing and modifying the biomaterial surface to target specific applications. For instance, Bandyopadhyay et $a{ }^{106}$ used an ethylene glycol-based electrolyte containing 1 vol\% $\mathrm{HF}$ to produce $\mathrm{TiO}_{2}$ nanotubes on Ti surfaces by AO, at a potential difference of $40 \mathrm{~V}$ for 1 hour followed by charge storage using electrothermal polarisation. These electrically polarised $\mathrm{TiO}_{2}$ nanotube surfaces enhanced the proliferation and osteogenic differentiation of human foetal osteoblasts by improving the surface hydrophilicity and bioactivity compared to untreated implants, and also promoted early-stage osseointegration in a rat distal femur model. Another recent application of AO was in exploring the responses of ASCs to nanostructured surfaces. As an example, Cowden et al. ${ }^{107}$ fabricated $\mathrm{TiO}_{2}$ nanotube surfaces by $\mathrm{AO}$, and found that the ASCs increased their proliferation and osteogenic differentiation on the modified surfaces in a manner that was dependent on the size of nanotubes, suggesting a possible application in modulating cell responses directly through orthopaedic implant coatings.

Under certain AO conditions, nanowires can form on top of $\mathrm{TiO}_{2}$ nanotubes, and their formation is mainly affected by voltage and treatment time. Hsu et al. ${ }^{108}$ proposed a 'strings of through holes' model to explain the mechanism of nanowire formation, consisting of four stages: (1) dissolving the nanotube wall near the upper end, causing thinning of the tube wall thickness; (2) forming strings of holes in the top section of the nanotube wall; (3) splitting into nanowires; and (4) folding and further thinning of nanowires. AO can also be an effective technique for inducing HA growth on treated surfaces. Nguyen et al. ${ }^{109}$ used an electrolyte containing calcium acetate, calcium glycerophosphate hydrate, and different concentrations of $\mathrm{Na}_{2} \mathrm{SO}_{4}$ to incorporate $\mathrm{Ca}$ and $\mathrm{P}$ into the oxide film of Ti6Al4V by AO. These Ca-containing films were bioactive and dissolved when immersed in simulated body fluid (SBF), enhancing the degree of supersaturation of the SBF solution and inducing the growth of HA on the sample surface. Lim and Cloe $^{110}$ developed another method for inducing bioactive apatite formation on an AO-treated Ti alloy, through a two-step loop process. The first step forms $\mathrm{TiO}_{2}$ nanotubes on the Ti6Al4V surface using AO, and the second step removes the nanotube layer by ultrasonic degradation, followed by plasma electrolytic oxidation (PEO) treatment in an electrolyte containing bioactive ions ( $\mathrm{Ca}, \mathrm{P} \pm \mathrm{Sr}, \mathrm{Mn}, \mathrm{Mg}, \mathrm{Zn}$, Si) to form bioactive apatite (Fig. 9A). This process was looped several times. As the number of loops increased, the diameter and size of nanotubes increased while the distance between nanotubes decreased, forming a mesh-shaped surface with increased surface roughness and bonding strength. After the third loop, the treated surface showed bioactive apatite formation with anatase and hydroxyapatite phases (Fig. 9B). 

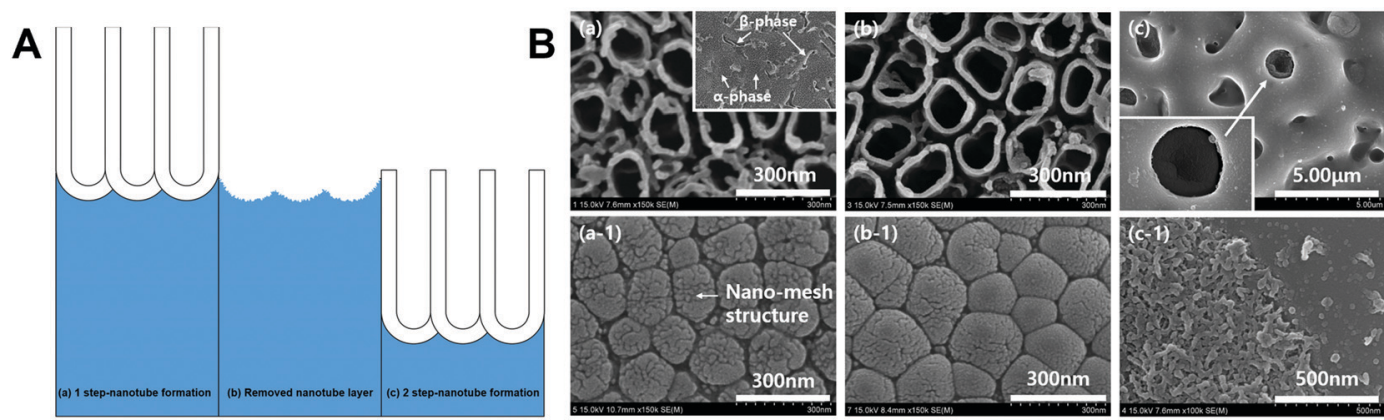

Fig. 9 (A) A two-step loop process to form bioactive apatite on the surface of Ti6Al4V and (B) SEM images of the surface morphology after loops one (left) and three (middle, right; the right images depict PEO in an electrolyte containing all bioactive ions (Ca, P, Sr, Mn, Mg, Zn, Si)). ${ }^{110}$ Reprinted with permission. Copyright 2019, Elsevier.

AO treatment can be additionally used to optimise the surface of Ti6Al4V implants produced by additive manufacturing techniques, such as selective laser melting and electron beam melting. These manufacturing methods for titanium implants are being increasingly explored as they couple good biocompatibility, corrosion resistance and strength with high implant customisability. ${ }^{111}$ However, to be practically useful for biomedical applications, certain shortcomings need to be overcome such as high porosity and poor surface finish. Methods such as electrically assisted ultrasonic nanocrystal surface modification $(\text { EA-UNSM })^{112}$ may be useful for this purpose. Alternatively, as reported by Ren et al., ${ }^{103}$ a layered micro/nano structure can be produced on 3D-printed Ti6Al4V implant surfaces by combining ultrasonic acid etching with AO. This surface promoted the proliferation and osteogenic differentiation of MC3T3-E1 cells by enhancing the surface hydrophilicity and bioactivity compared with the untreated implant, and also increased bone formation and osseointegration in a rat femoral defect model.

2.3.5 Micro arc oxidation. Micro arc oxidation (MAO), also known as PEO, is an upgrade of $\mathrm{AO}$ and an effective and convenient surface modification method for producing firmly adherent oxide films on the surface of metals such as $\mathrm{Al}, \mathrm{Mg}$, Ti, and their alloys. The surface formed through MAO is porous and relatively rough, with high hardness and corrosion resistance. The composition of the electrolyte has a significant influence on coating formation through MAO. For instance, Wang et al. ${ }^{113}$ formed bioactive ceramic coatings on Ti6Al4V in two different electrolytes, and found that MAO coatings prepared from a silicate electrolyte grew rapidly and corroded faster in SBF, while those prepared from a calcium phosphate electrolyte showed a great surface microstructure and corrosion resistance. Li et al. ${ }^{114}$ used a duplex coating process where MAO was used to fabricate the $\mathrm{TiO}_{2}$ coating, followed by further modification by electrochemical treatment in alkaline solution (MAO-AK). The MAO-AK coating showed changes in nanomorphology compared to the MAO coating but retained a similar micro-morphology (Fig. 10). Both coatings were found to significantly enhance cell adhesion and osteogenic differentiation by mediating the integrin $\beta 1$ signalling pathway. When implanted into the canine femur, the MAO-AK coating showed a significantly higher bone formation speed and boneimplant contact ratio.

Metal ions such as Al, V, Co, Cr and Mo in implant materials can have a negative effect on cell viability, and such effects are often closely related to their concentration. ${ }^{115}$ A possible approach for increasing the biological activity of the Ti6Al4V alloy is to inhibit the release of $\mathrm{Al}$ and $\mathrm{V}$ from the implant. Guan et al. ${ }^{17}$ presented a method to form a porous oxide coating on Ti6Al4V through MAO that reduces the $\mathrm{Al}$ and $\mathrm{V}$ content of the coating, by using a $\mathrm{Na}_{2} \mathrm{~B}_{4} \mathrm{O}_{7}$ electrolyte added with $\mathrm{KOH}$. It was found that an increased concentration of $\mathrm{KOH}$ in the electrolyte led to better removal of $\mathrm{Al}$ and $\mathrm{V}$. The modified MAO coating showed superhydrophilicity and excellent cytocompatibility with MC3T3 cells.

To further improve the performance of MAO coatings on $\mathrm{Ti}$ substrates, some elements that support bone formation or have antibacterial properties have been incorporated into the coating. ${ }^{34,116-119}$ Approaches to include bioactive elements such as $\mathrm{Si}, \mathrm{Sr}$, and $\mathrm{Mg}$ have been effective, but antibacterial elements such as $\mathrm{Zn}, \mathrm{Cu}$, and $\mathrm{Ag}$ cannot be easily fixed on the implant surface using MAO, which does not allow the coating to confer a lasting antibacterial effect. Zhao et al. ${ }^{116}$ used MAO to prepare $\mathrm{TiO}_{2}$ microporous coatings with Si uniformly distributed on the coating surface, and found that Si doping did not change the surface morphology, roughness, or phase composition. The Si-incorporated surface increased in vitro osteoblast adhesion, spreading, proliferation, and differentiation, as well as early stage in vivo osseointegration in a rabbit model. Antibacterial properties were not tested in this study. Li et al. ${ }^{117}$ used MAO to prepare porous $\mathrm{TiO}_{2}$ coatings doped with $\mathrm{Ca}$ and $\mathrm{Sr}$, by adding $\mathrm{CaO}$ and $\mathrm{SrO}$ in tetraborate electrolytes. The resulting coatings were superhydrophilic and highly biocompatible, and allowed easy release of $\mathrm{Ca}$ and $\mathrm{Sr}$ into aqueous solution. When tested using human BMSCs, the coating doped with $\mathrm{Ca}$ and $\mathrm{Sr}$ showed significantly higher cell proliferation compared to that doped with only Ca or Sr. Another group doped different concentrations of $\mathrm{Mg}$ into $\mathrm{TiO}_{2}$ coatings by MAO, and showed that the electrolyte with $2 \mathrm{~g} \mathrm{~L}^{-1}$ magnesium acetate produced coatings with the best ability to encourage rat BMSC adhesion, proliferation, and osteogenic differentiation. ${ }^{120}$

Strategies to incorporate antibacterial elements include a two-step method for preparing an Ag-doped $\mathrm{TiO}_{2}$ surface, 

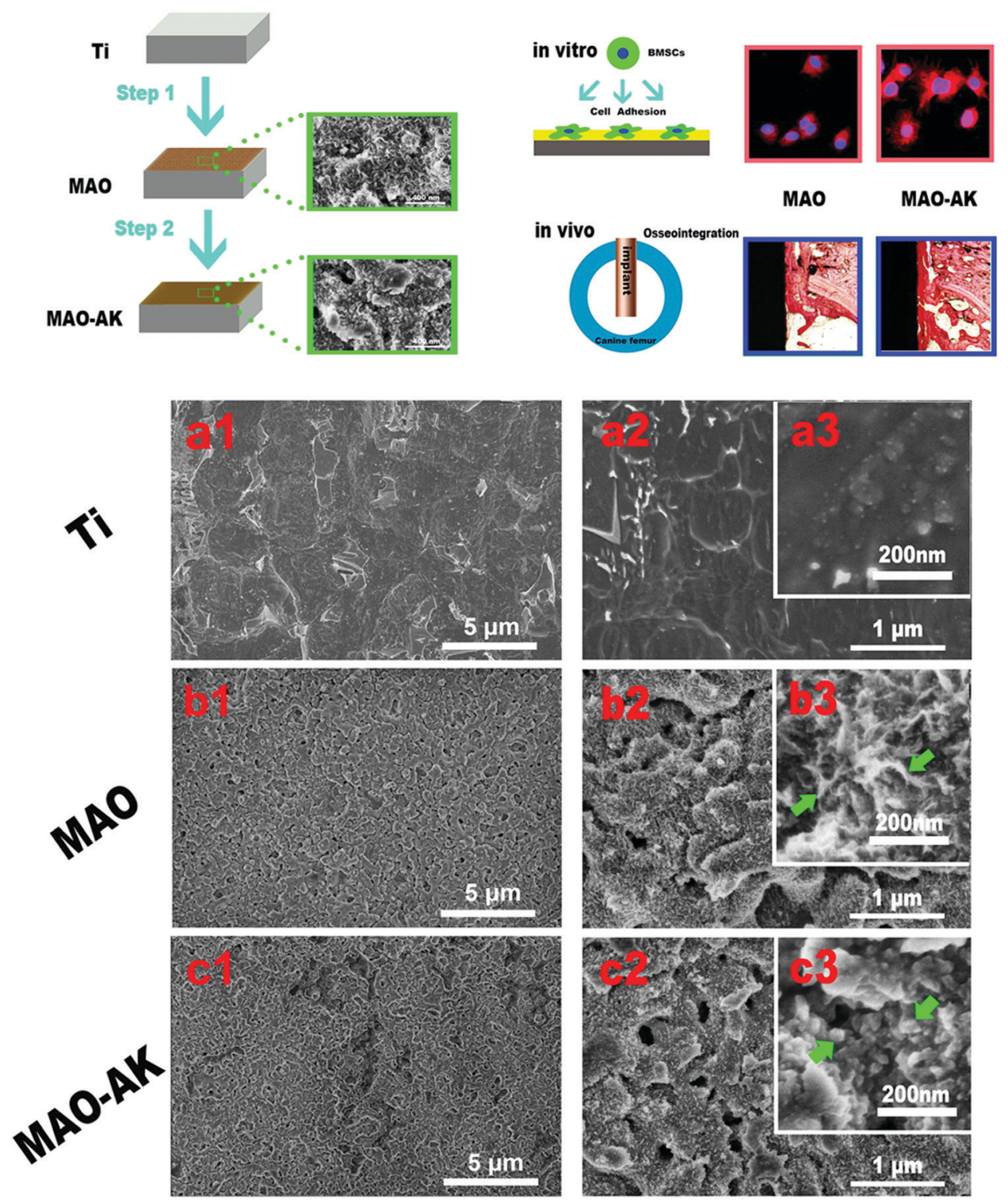

Fig. 10 Changes in the nano-morphology of Ti samples, treated or not with MAO and post-modified or not with electrochemical treatment (MAOAK). ${ }^{114}$ Green arrows: b3 = petal-like nanostructures; $c 3=$ granular nanostructures. Reprinted with permission. Copyright 2016, American Chemical Society.

described by Durdu et al. ${ }^{118}$ This method first used thermal evaporation-physical vapor deposition (TE-PVD) to deposit a thin Ag layer on the Ti surface, followed by coating the surface using MAO in sodium silicate and potassium hydroxide. Energy dispersive spectroscopy (EDS) analysis indicated that $\mathrm{Ag}$ was released from the inner $\mathrm{Ag}$ layer through the surface pores, and was localised only around the region of the pores. Compared to surfaces treated only with MAO, the Ag-doped MAO surface significantly reduced the active colony ratio of $E$. coli and $S$. aureus (both by $>50 \%$ ), as well as increased surface wettability and in vitro apatite formation. However, cytotoxicity or biocompatibility tests were not reported. Ye et al. ${ }^{119}$ used MAO to produce $\mathrm{Zn}$-doped $\mathrm{TiO}_{2}$ coatings with excellent bactericidal activity and osseointegration ability. The coating had a bilayer structure, where the amorphous outer layer consisted of $\mathrm{Ti}, \mathrm{O}$, and $\mathrm{Zn}$ with $\mathrm{Zn}$ doped in the form of weakened $\mathrm{Zn}-\mathrm{O}$ bonds, and the inner layer was partially crystallised with nanocrystalline $\mathrm{TiO}_{2}$ and $\mathrm{Zn}_{2} \mathrm{TiO}_{4}$ with an embedded amorphous matrix. The weakened $\mathrm{Zn}-\mathrm{O}$ bonds were found to be the key factor controlling $\mathrm{Zn}^{2+}$ release and ROS production. When produced at higher voltage (530 V compared to 300 or $400 \mathrm{~V}$ ), enhanced ROS formation on the MAO coating led to bacterial cell wall breakage, coupled with enhanced $\mathrm{Zn}^{2+}$ release and extracellular $\mathrm{H}_{2} \mathrm{O}_{2}$ formation causing increased intracellular ROS levels, which acted in parallel to result in bacterial death. However, coatings with excessive Zn concentration were seen to induce excessive ROS levels and lead to bone cell apoptosis. The coating produced at $400 \mathrm{~V}$ showed the best balance of performance, which promoted osseointegration in rat tibiae that were uninfected or infected with $S$. aureus. 
HA is a popular implant coating material due to its high biocompatibility and stable chemical properties, and its incorporation onto Ti implants using MAO has been explored. Studies have reported that an MAO coating decorated with HA nanostructures could provide a suitable microenvironment for promoting bone formation, immunomodulation and angiogenesis, which was termed "osteo-immunomodulation". ${ }^{32,33}$ In the first study, Bai et al. ${ }^{32}$ prepared a microporous HA-modified $\mathrm{TiO}_{2}$ coating using MAO, followed by annealing at different temperatures to tune the physical and chemical properties of the coating. Annealing at $650{ }^{\circ} \mathrm{C}$ was found to produce the most favourable coating properties, including a hybrid micro-nano morphology, superhydrophilicity, and HA NPs with high crystallinity. In vitro tests using osteoblasts and endothelial cells and in vivo implantation in a rabbit model demonstrated the ability of this coating to promote bone formation and angiogenesis, as well as modulate the immune response in macrophages. In the second study, Bai et al. ${ }^{33}$ prepared two types of microporous surfaces which were respectively decorated with HA NPs and nanorods. MAO was used followed by steam-hydrothermal treatment (SHT), whereby the nanostructure of HA was altered by adjusting the SHT processing time. In vitro and in vivo experiments indicated that MAO surfaces decorated with HA NPs were conducive to osteo-immunomodulation, bone formation, and angiogenesis, while those decorated with HA nanorods did not show the same effects. The key signalling pathways involved were thought to be related to TGF- $\beta$, OPG/RANKL, and VEGF. In another approach to form a HA-doped coating on a Ti substrate using MAO, Qaid et al. ${ }^{121}$ synthesised phase pure HA from calcined eggshells, and added different concentrations of this into a tri-sodium orthophosphate $\left(\mathrm{Na}_{3} \mathrm{PO}_{4} \cdot 12 \mathrm{H}_{2} \mathrm{O}\right)$ based electrolyte solution in a one-step MAO process. The MAO coating produced using a $1.5 \mathrm{~g} \mathrm{~L}^{-1}$ concentration of eggshell-derived HA was found to give the best adhesive strength and corrosion resistance. Tests for biocompatibility or biological activity of the coating were not performed.

\subsection{Biological modification methods}

Biological modification methods involve fixing specific bioactive molecules such as proteins, peptides, and enzymes on the implant surface. After implantation in the body, the biologically modified implant surface induces the adsorption of different proteins from the internal environment to form a protein layer. These bioactive layers can provide active sites for a variety of biological responses involving cellular receptors, leading to downstream effects such as cell adhesion, migration, proliferation, differentiation, and apoptosis, which can contribute to tissue formation, osseointegration, and other biological processes. Compared to physical and chemical modification methods, biological surface modification is more direct and efficient. However, the preservation time of bioactive molecules on the implant surface is typically limited by a set of environmental conditions including air, temperature, humidity, light, and $\mathrm{pH}$, which increase the product cost and restrict the large-scale manufacturing and use of implants with biologically modified surfaces.

2.4.1 Layer by layer self-assembly. Self-assembly is a technique in which the basic structural units spontaneously form an ordered structure. Layer by layer self-assembly (LBL) is a method used for preparing thin polyelectrolyte multilayers by alternating the deposition of oppositely charged polyelectrolytes on a charged substrate, which can be applied as an implant coating strategy. Gregurec et al. ${ }^{122}$ produced a bioinspired coating onto a $\mathrm{TiO}_{2}$ layer by $\mathrm{LBL}$, in the form of a self-assembled and chemically crosslinked biopolymer film composed of alginate and collagen. The coating displayed a fibrillar morphology with fibre diameter and length mimicking that of the bone extracellular matrix, which enhanced the adhesion of MC3T3-E1 cells compared to the unmodified $\mathrm{TiO}_{2}$ surface. He et al. ${ }^{123}$ prepared a micro-structured surface on Ti samples using a double acid etching method, followed by LBL to create a gelatin-chitosan multilayer coating loaded with SEW2871 (a macrophage recruitment agent). This coating was effective in inducing the recruitment of macrophages, as well as enhancing their anti-inflammatory response and reducing pro-inflammatory response. This immunomodulation effect improved the in vitro osteogenic differentiation of rat BMSCs and in vivo osseointegration in the rat femur.

Implant coatings with antioxidant properties may help with bone healing after implant surgery by reducing oxidative stress from excess ROS production. Chen et al. ${ }^{124}$ constructed a multilayer coating with antioxidant activity on a Ti substrate, consisting of chitosan-catechol, gelatin, and HA nanofibres. This coating effectively protected osteoblasts from oxidative damage, by regulating gene expression related to cell adhesion molecules (integrin $\alpha \mathrm{v}, \beta_{3}, \mathrm{CDH} 11, \mathrm{CDH} 2$ ), as well as by regulating cell adhesion and anti-apoptotic proteins ( $p$-MYPT1, $p$-FAK, $p$-Akt, Bcl-2). The coating also promoted in vitro osteoblast differentiation and early bone healing in vivo in a rabbit model. Building on this work, the same group used the multilayer coating as a platform to investigate the coupling between osteogenesis and angiogenesis during bone healing. ${ }^{125}$ The coating was found to mediate in vitro communication between co-cultured rat ASCs and human umbilical vein endothelial cells (HUVECs) through cell-matrix interactions that enhanced their paracrine effects (Fig. 11A). When grown in co-culture in the presence of the multilayer coating, both ASCs and HUVECs increased their transmigration, as well as gene or protein expression of angiogenic factors such as SDF-1 and VEGF, compared to cells grown on tissue culture plastic or uncoated Ti. There was some evidence of bone formation when $\mathrm{Ti}$ samples with the multilayer coating were implanted into rats subcutaneously or in the femur, but the process of in vivo osseointegration requires further investigation.

2.4.2 Other biological modification methods. Inspired by the natural composition, structure, and physiological characteristics of bone, a range of modification methods have emerged for creating bioinspired surfaces to encourage implant osseointegration and new bone formation. ${ }^{42}$ Various methods have been used to immobilise bioactive molecules such as 

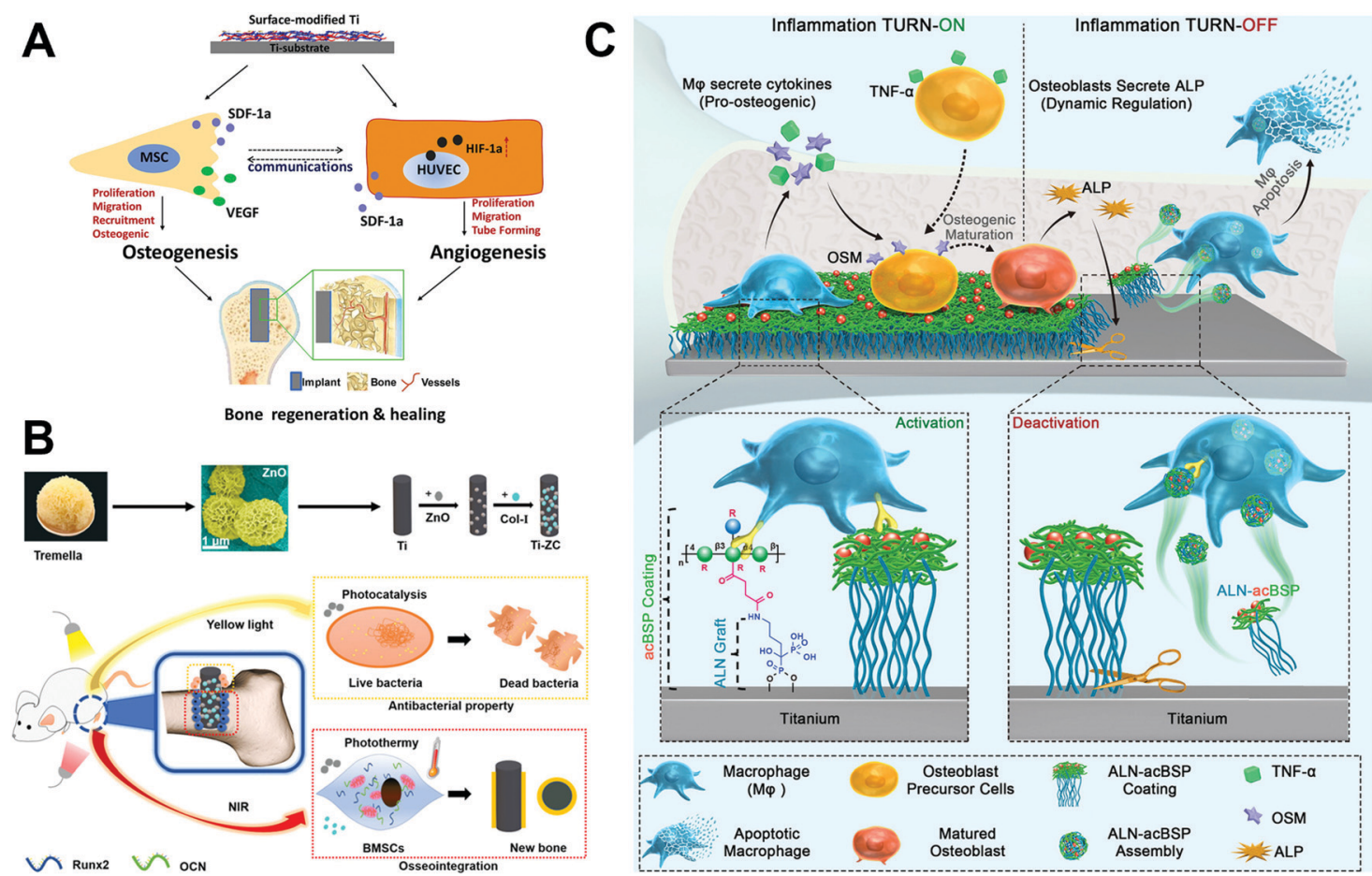

Fig. 11 Schematic illustration of (A) a multilayer biological coating on a Ti substrate produced by LBL that mediates coupling of osteogenesis and angiogenesis to promote bone healing, ${ }^{125}$ (B) a tremella-like coating that could respond to yellow light and near infrared light to provide antibacterial and osteogenic functions, ${ }^{126}$ and (C) a bio-responsive, "bridge-burning" coating to turn on and turn off macrophage activity on implants to provide osteo-immunomodulation and help bone formation. ${ }^{34}$ Reprinted with permission. (A) Copyright 2018, Elsevier; (B) Copyright 2020, American Chemical Society; (C) Copyright 2020, John Wiley and Sons.

proteins, enzymes, peptides, glycans, and polydopamine on metal implant surfaces to achieve remarkable biological effects. $^{34,35,126-129}$ Some studies have attempted to fabricate biological coatings with both antibacterial and osteogenic functions. Zhao et al. ${ }^{126}$ designed a tremella-like coating, inspired by the phenomenon that tremella can absorb nutrients in the cooking liquid after vesiculation. Tremellalike $\mathrm{ZnO}$ was synthesised and applied together with collagen type I to form a coating on Ti implant surfaces (Fig. 11B). The coating could respond to yellow light irradiation, showing photocatalytic performance and providing antibacterial activity against $S$. aureus and E. coli. Under near infrared (NIR) light, the coating showed photothermal performance and promoted the osteogenic behaviour of rat BMSCs, as well as implant osseointegration in a rat model. This coating has potential to be applied for the treatment of peri-implant diseases, but its long-term stability and toxicity require further evaluation. Through a different approach, Chen et al. ${ }^{127}$ immobilised an innovative fusion peptide containing an HHC36 antimicrobial sequence and a $\mathrm{QK}$ angiogenic sequence on the Ti implant surface, through a $\mathrm{Cu}(\mathrm{I})$-catalyzed azide-alkyne cycloaddition process promoted by sodium borohydride. The coated implant could simultaneously enhance angiogenic behaviour in HUVECs and osteogenic activity in human BMSCs, as well as kill $96-99 \%$ of various bacterial strains (S. aureus, E. coli, $P$. aeruginosa, and MRSA) in vitro. When tested in rabbits, the coated implant could kill $99.63 \%$ of $S$. aureus in the infection model, and it simultaneously promoted vascularisation and osseointegration in the non-infection model.

The concept of "osteo-immunomodulation" has gained increasing understanding and recognition of its importance in bone healing, with emerging strategies aimed at biomaterial modifications that modulate the host immune environment to provide anti-inflammatory and anti-infective properties. ${ }^{130}$

Recent studies have focused on producing new coatings to regulate macrophage activity on implant surfaces. Wang et al. ${ }^{34}$ designed a bio-responsive, endogenously triggered, "bridgeburning" coating to regulate macrophage activity on the $\mathrm{Ti}$ surface, containing acetyl glucomannan (acBSP) as a macrophage-activating glycan covalently crosslinked by alendronate (ALN) as a macrophage-killing bisphosphonate (Fig. 11C). The specific "bridge-burning" process used by the coating to regulate biological response is divided into two steps: (1) After implantation, the acBSP activates host macrophages to secrete pro-osteogenic cytokines, "turning on" to promote bone differentiation. (2) An increasing number of mature bone cells release ALP, cleaving the ALN-acBSP complexes from the implant surface which are preferentially internalised by inflammatory macrophages. This "turning off" induces macrophage apoptosis to suppress inflammation and promote healing. When tested in a rat osteoporosis model, the coated implant significantly enhanced bone-implant integration (88.4\% higher contact ratio) compared to uncoated Ti. In another study, Shi et al. ${ }^{35}$ used a biologically derived 
component as an implant coating. Zymosan, a fungal component, was covalently grafted onto $\mathrm{Ti}$ implants to target and regulate macrophage activity. This polysaccharide coating could activate host macrophages through toll-like receptors (TLR) to produce osteogenic and angiogenic factors. In vivo testing in the rat femur indicated that a medium dose of zymosan in the coating $\left(0.1 \mu \mathrm{g} \mathrm{mm} \mathrm{mm}^{-2}\right)$ could significantly improve osseointegration, without inducing severe inflammation as occurred with the high dose group.

Dopamine is the most abundant catecholamine neurotransmitter in the brain, which regulates various physiological functions of the central nervous system. Polydopamine (PDA) is a mussel-derived biomimetic material that forms by self-polymerisation from dopamine in a weakly alkaline environment. In 2007, inspired by the composition of adhesive proteins in mussels, Lee et al. ${ }^{128}$ first reported that PDA could be coated on almost any solid material surface. Since then, coatings containing PDA have been widely explored and applied in various biomaterial modifications. PDA has several advantages as a biological coating material: (1) PDA can enhance the biocompatibility and hydrophilicity of the implant surface to promote adhesion and spreading of diverse cell types, including chondrocytes, endothelial cells, and BMSCs, even on superhydrophobic surfaces..$^{131-133}$ (2) PDA can enhance the osteogenic differentiation of mesenchymal stem cells (MSCs), by increasing their expression levels of osteogenic genes $^{134}$ or by promoting their calcium mineralisation through simulating the biological environment of the bone extracellular matrix. ${ }^{135}$ Recently, Wang et al. ${ }^{129}$ fabricated PDA coatings on polyetheretherketone (PEEK), Ti6Al4V and HA as representative polymer, metal and ceramic biomaterials, by immersing samples in dopamine solution at $37{ }^{\circ} \mathrm{C}$ for 24 hours. The PDA coating was found to significantly improve the hydrophilicity of the material surface, and directly enhance the adhesion, proliferation and osteogenic differentiation of rat BMSCs through FAK and p38 signalling pathways. An in vivo study in the rat femur using coated and uncoated PEEK as representative implant materials confirmed that the PDA coating significantly enhanced osseointegration and accelerated new bone formation.

\section{Perspectives and outlook}

Traditional Ti and Ti alloy implants have a low probability of long-term clinical success and may have a short service life. Secondary or even multiple surgical revisions may be required due to implant failure, particularly in younger patients. ${ }^{136}$ Surface modification technology is evolving as an interdisciplinary field and a primary means for improving Ti implant osseointegration. Modification strategies could be inspired by a variety of bone-related structures and processes, including the inorganic and organic phases of bone, and its immune system and vasculature. $^{42}$ The outcomes of modification could involve improvements in surface hydrophilicity, antibacterial activity, antithrombotic property, corrosion resistance, durability, biocompatibility, and even bioactivity. In this review, we introduced a range of surface modification methods for $\mathrm{Ti}$ implants from the recent literature, categorised them according to the primary mechanism for coating formation, and critically analysed their coating effects and applications. This knowledge synthesis is important for providing inspiration for further research to translate as well as extend the applications of surface modified implant materials in biomedical applications.

Each type of surface modification method discussed in this review has a different set of characteristics, which are associated with certain advantages and disadvantages as summarised in Table 3 . It can be seen that some factors are present for all modification methods that may limit their ability to be adapted for large-scale manufacturing or clinical application. Research is being undertaken in this field to develop new coating techniques that may avoid or reduce the limitations of existing approaches. For instance, Song et al. ${ }^{137}$ recently developed an alkalinity-activated solid-state dewetting technique (AAD), producing quasi-periodic nanoscale pimplelike $\mathrm{TiO}_{2-x}$ structures on the Ti6Al4V surface that cannot be formed through existing surface treatments. The modified surface showed strong interfacial effects including increased implant surface energy and hydrophilicity, and antiinflammatory and pro-regenerative functions by modulating the cross-talk between osteoblasts and macrophages. The coated implants demonstrated a strong ability to induce osseointegration and osteo-immunomodulation in a rat tibial defect model.

Presently, it is challenging to combine the desirable characteristics of wear resistance, corrosion resistance, biocompatibility or bioactivity, and antibacterial activity in biomedical implants solely through surface modification technology. A primary future goal of this research area is to develop new multilayer composite coatings for biomedical implants with a combination of desirable properties, which can serve stably for a long period of time in the biological environment, by integrating surface modification with other technologies. As described earlier in this review, the combination of modification methods, such as thermal oxidation and AO, with additive manufacturing may provide new strategies for overcoming technological barriers. ${ }^{103,111,112}$ Some of the early work on surface modification using additive manufacturing led to the development of porous $\mathrm{Ti}^{146,147}$ or $\mathrm{Ta}^{148,149}$ coatings with $3 \mathrm{D}$ interconnected porosity reaching $70 \%$. With the assistance of computer-aided design (CAD) and surface optimisation technology, 3D-printed bone implants can now be fabricated which simultaneously possess gradient porous structures and functional surfaces, thereby greatly increasing their ability for osseointegration. ${ }^{150,151}$ As an example, Mitra et al. ${ }^{152}$ successfully fabricated Ti-tantalum (Ta) alloy implants with multiscale structural variations by $3 \mathrm{D}$ printing. With combined micro-porosity and nanoscale surface features, the Ti-Ta alloys showed superior biological performance compared with commercially pure $\mathrm{Ti}$, and had great potential to be developed further as part of the next generation of implant materials. Reflecting the current status of research, this review focused on 
Table 3 Comparison of different surface modification methods

\begin{tabular}{|c|c|c|}
\hline Method & Advantages & Disadvantages \\
\hline PIII $^{65,70}$ & $\begin{array}{l}\text { - Good biocompatibility } \\
\text { - Versatile and less hazardous process due to low } \\
\text { temperature } \\
\text { - Thin injection layer does not affect material } \\
\text { properties }\end{array}$ & $\begin{array}{l}\text { - Limited in achieving large-scale industrial applications } \\
\text { - Chance of implanting undesired impurities in the plasma } \\
\text { - May be difficult to achieve uniform ion implantation over a large area, } \\
\text { or monitor precise dosage }\end{array}$ \\
\hline $\begin{array}{l}\text { Laser } \\
\text { cladding }^{71,72,138}\end{array}$ & $\begin{array}{l}\text { - Can prepare coatings with a fine grained and } \\
\text { compact structure } \\
\text { - High bonding strength of the coating to the } \\
\text { substrate } \\
\text { - Wide selection of the cladding layer and substrates } \\
\text { - Use of laser is clean and pollution-free, and easy to } \\
\text { realise automation }\end{array}$ & $\begin{array}{l}\text { - This technology has been rarely applied in clinical practice due to its } \\
\text { short history of development, currently mostly applied in laboratory } \\
\text { settings } \\
\text { - Expensive equipment and complex process may limit its large-scale } \\
\text { application }\end{array}$ \\
\hline $\operatorname{SLA}^{139,140}$ & $\begin{array}{l}\text { - Can obtain surface micropores of different sizes } \\
\text { - Technology is economical, convenient, and mature }\end{array}$ & $\begin{array}{l}\text { - Little control over surface structure } \\
\text { - Produces an irregular surface with great fluctuations in roughness } \\
\text { values }\end{array}$ \\
\hline $\begin{array}{l}\text { Thermal } \\
\text { oxidation }^{78,80,81,141}\end{array}$ & $\begin{array}{l}\text { - Coating can improve the mechanical properties of } \\
\text { the substrate } \\
\text { - Can be used to enhance the bonding strength } \\
\text { between coating and substrate } \\
\text { - A simple, convenient, and cost-effective method }\end{array}$ & $\begin{array}{l}\text { - Oxide debonding occurs at high temperatures or oxidation times } \\
\text { - Cracks can occur due to thermal stress and associated forces } \\
\text { - Low compactness of the surface } \\
\text { - Process has poor control }\end{array}$ \\
\hline
\end{tabular}

$\mathrm{MAO}^{31,116}$

- Can be used to produce porous coatings with high - Power supply consumes a large amount of energy hardness and corrosion resistance, that are firmly adherent on the substrate

- Can be used for in situ coating formation

- Lack of in-depth understanding of the ion film-forming reaction in the electrolyte, as well as factors influencing gradient film design - Ability of the technology to allow rapid large-scale preparation of stable implant coatings has not been confirmed

LBL $^{124,125} \quad$ - Widely used technique for preparing multilayered biological coatings

- Process is time-consuming and has low production efficiency, often requiring hours to days to make a batch of samples depending on the number of layers

- Applicable to a wide range of substrates and provides controllable coating thickness

- Simple preparation process and low preparation

temperature

- Repetitive deposition limits the number of coating layers and hence coating thickness, which may not be suitable for certain applications - Repetitive deposition may cause cross-contamination of different

- Strong bonding force between coating and substrate stock materials used for coating fabrication 
surface modifications in the two-dimensional plane, while modifications of three-dimensional Ti scaffold surfaces have been rarely reported. In this emerging area, Rifai et al. ${ }^{153}$ prepared a polycrystalline diamond coating (PCD) on three-dimensional Ti6Al4V scaffold implants by additive manufacturing and chemical vapour deposition. This implant was found to significantly resist bacterial attachment and improve osseointegration, providing new inspiration for patient-specific implant design.

In addition to the modification methods discussed in this review, micro-printing techniques that involve a combination of physical and chemical mechanisms can be used to produce micro-patterns on implant surfaces, constructing an ordered microenvironment for cell growth. By combining geometric micro-patterns with controllable size and chemical action, it is possible to achieve greater control over cell behaviour and produce specific cell morphologies and structures, such as spheroids. ${ }^{154}$ Using the same principles, the generation of precisely controlled surface micro-patterns could enable implants to perform advanced functions. For instance, Gilabert-Chirivella et $a .^{155}$ etched surface microgrooves on a Ti implant using a modified 3D printer, and fixed chitosan to the bottom of the grooves without the need for covalent bonding, endowing the implant with antibacterial properties and with the ability to support preferential pre-osteoblast adhesion. Other techniques, including lithography, soft etching, electrochemical micromachining, and laser etching, can be used to produce fine micro-patterns at smaller length scales. Among these, microcontact printing is a low cost technique that provides high reliability and versatility, and has been widely applied in constructing cell culture platforms, biosensing platforms, and devices for other biological applications, ${ }^{156}$ and it could be a useful technique to consider for implant coatings.

Recent research has seen an emergence of studies that combine physical, chemical and biological modification approaches to endow implant surfaces with complex biological functions. For instance, Li et al. ${ }^{157}$ prepared a micronanostructured HA coating on Ti by MAO, and then loaded chitosan as an antibacterial agent through dip-coating to improve the surface biological and antibacterial properties. Drug loading has also been applied to Ti surfaces modified using various techniques to provide antibacterial function, involving mostly broad-spectrum antibiotics such as gentamicin, cephalothin, simvastatin, vancomycin, and tobramycin. ${ }^{158-162}$ Nevertheless, implant surfaces with a biological component still face a number of challenges in their translation to clinical applications, including considerations around implant stability, reliability, disinfection, and storage. Further research is required to optimise such implant designs and gain a better understanding of the coating mechanisms and effects, active ingredients, toxicity limits, and possible biological interactions. As an example, multifunctional PDA-based coatings are now being increasingly studied to address infection and aseptic loosening of orthopaedic implants. ${ }^{163}$

Surface modification of Ti and its alloys can greatly improve the osseointegration and antibacterial properties of biomedical implants, bearing great significance to the orthopaedics field and the health and well-being of patients. A variety of modification techniques can contribute to modulating the implant-bone interface and lead to better outcomes of osseointegration and/or osteogenesis. ${ }^{164}$ Methods such as PST, SLA, and $\mathrm{AO}$ so far remain the most popular surface modification strategies since they do not require much expensive, customised, or highly specialised equipment, are controllable and reproducible, and allow efficient production for scale-up manufacturing. ${ }^{165}$ For new implant coating techniques to be considered for clinical translation, their performance needs to be first verified in large animal models with clinically relevant skeletal defects and similar mechanisms and time frames of bone healing as humans. This, together with the costs of industrial upscaling and the cost-effectiveness of the coating method itself, constitutes a rate-limiting step for the majority of techniques in development. For these reasons, only a small number of new coating technologies have reached clinical trials and commercialisation, while most have remained in the preclinical phase. ${ }^{165}$ Other studies have focused on developing and optimising the process of new techniques, such as more refined nanolithography, rather than undertaking extensive in vitro and/or in vivo investigations to understand the biological effects of the coating, or the mechanisms driving cell and tissue responses to the coating. ${ }^{166-168}$ Looking into the future, it is of great scientific significance and practical value to study and combine various surface modification approaches, as well as to conduct physiologically relevant testing, for developing the next generation of orthopaedic implant coatings with the combined functions of inducing successful bone healing while preventing adverse reactions at the implant site.

\section{Conflicts of interest}

There are no conflicts to declare.

\section{Acknowledgements}

The authors acknowledge the support of the National Key R\&D Program of China (2021YFE0113000), the National Natural Science Foundation of China (NSFC; 51872318), Shenzhen Science and Technology Research Funding (JCYJ20210324120012034), the National Health and Medical Research Council (NHMRC, Australia; GNT1120249), and the Australian Research Council Training Centre for Innovative BioEngineering (IC170100022).

\section{References}

1 M. C. S. Inacio, S. E. Graves, N. L. Pratt, E. E. Roughead and S. Nemes, Increase in total joint arthroplasty projected from 2014 to 2046 in Australia: A conservative local model with international implications, Clin. Orthop. Relat. Res., 2017, 475, 2130-2137.

2 H. M. Kremers, D. R. Larson, C. S. Crowson, W. K. Kremers, R. E. Washington, C. A. Steiner, 
W. A. Jiranek and D. J. Berry, Prevalence of total hip and knee replacement in the United States, J. Bone Jt. Surg., Am. Vol., 2015, 97, 1386.

3 D. M. Daubert, B. F. Weinstein, S. Bordin, B. G. Leroux and T. F. Flemmig, Prevalence and predictive factors for periimplant disease and implant failure: A cross-sectional analysis, J. Periodontol., 2015, 86, 337-347.

4 B. Klinge and J. Meyle, Peri-implant tissue destruction. The Third EAO Consensus Conference 2012, Clin. Oral Implants Res., 2012, 23, 108-110.

5 D. Duraccio, F. Mussano and M. G. Faga, Biomaterials for dental implants: current and future trends, J. Mater. Sci., 2015, 50, 4779-4812.

6 Y. F. Ding, R. W. Li, M. Nakai, T. Majumdar, D. H. Zhang, M. Niinomi, N. Birbilis, P. N. Smith and X. B. Chen, Osteoanabolic implant materials for orthopedic treatment, Adv. Healthcare Mater., 2016, 5, 1740-1752.

7 M. Niinomi, Metallic biomaterials, J. Artif. Organs, 2008, 11, 105-110.

8 W. S. W. Harun, R. I. M. Asri, J. Alias, F. H. Zulkifli, K. Kadirgama, S. A. C. Ghani and J. H. M. Shariffuddin, A comprehensive review of hydroxyapatite-based coatings adhesion on metallic biomaterials, Ceram. Int., 2018, 44, 1250-1268.

9 M. Iafisco, I. Foltran, S. Sabbatini, G. Tosi and N. Roveri, Electrospun nanostructured fibers of collagen-biomimetic apatite on titanium alloy, Bioinorg. Chem. Appl., 2012, 2012, 123953.

10 D. D. Bosshardt, V. Chappuis and D. Buser, Osseointegration of titanium, titanium alloy and zirconia dental implants: current knowledge and open questions, Periodontology, 2017, 73, 22-40.

11 Y. Zheng, J. Li, X. Liu and J. Sun, Antimicrobial and osteogenic effect of Ag-implanted titanium with a nanostructured surface, Int. J. Nanomed., 2012, 7, 875-884.

12 N. J. Hickok and I. M. Shapiro, Immobilized antibiotics to prevent orthopaedic implant infections, Adv. Drug Delivery Rev., 2012, 64, 1165-1176.

13 T. Monteiro, M. Wysocka, E. Tellez, O. Monteiro, L. Spencer, E. Veiga, S. Monteiro, C. de Pina, D. Gonçalves, S. de Pina, A. Ludgero-Correia, J. Moreno, T. Conceição, M. Aires-deSousa, H. de Lencastre, L. J. Gray, M. Pareek, D. R. Jenkins, S. Beleza, M. R. Oggioni and I. I. Araujo, A five-year retrospective study shows increasing rates of antimicrobial drug resistance in Cabo Verde for both Staphylococcus aureus and Escherichia coli, J. Glob. Antimicrob. Resist., 2020, 22, 483-487.

14 B. Li and T. J. Webster, Bacteria antibiotic resistance: New challenges and opportunities for implant-associated orthopedic infections, J. Orthop. Res., 2018, 36, 22-32.

15 S. A. Alves, R. Bayón, V. S. de Viteri, M. P. Garcia, A. Igartua, M. H. Fernandes and L. A. Rocha, Tribocorrosion Behavior of Calcium- and Phosphorous-Enriched Titanium Oxide Films and Study of Osteoblast Interactions for Dental Implants, J. Bio- Tribo-Corros., 2015, 1, 1-21.

16 N. S. Manam, W. S. W. Harun, D. N. A. Shri, S. A. C. Ghani, T. Kurniawan, M. H. Ismail and M. H. I. Ibrahim, Study of corrosion in biocompatible metals for implants: A review, J. Alloys Compd., 2017, 701, 698-715.

17 S. Guan, M. Qi, C. Wang, S. Wang and W. Wang, Enhanced cytocompatibility of Ti6Al4V alloy through selective removal of $\mathrm{Al}$ and $\mathrm{V}$ from the hierarchical micro-arc oxidation coating, Appl. Surf. Sci., 2021, 541, 148547.

18 E. M. Lotz, M. B. Berger, Z. Schwartz and B. D. Boyan, Regulation of osteoclasts by osteoblast lineage cells depends on titanium implant surface properties, Acta Biomater., 2018, 68, 296-307.

19 P.-I. Branemark, Osseointegration and its experimental background, J. Prosthet. Dent., 1983, 50, 399-410.

20 S. Migita and K. Araki, Effect of nanometer scale surface roughness of titanium for osteoblast function, AIMS Bioeng., 2017, 4, 162-170.

21 R. Rasouli, A. Barhoum and H. Uludag, A review of nanostructured surfaces and materials for dental implants: surface coating, patterning and functionalization for improved performance, Biomater. Sci., 2018, 6, 1312-1338.

22 G. Wang, S. Moya, Z. Lu, D. Gregurec and H. Zreiqat, Enhancing orthopedic implant bioactivity: refining the nanotopography, Nanomedicine, 2015, 10, 1327-1341.

23 J. T. B. Ratnayake, M. Mucalo and G. J. Dias, Substituted hydroxyapatites for bone regeneration: A review of current trends, J. Biomed. Mater. Res., Part B, 2017, 105, 1285-1299.

24 M. Al-Amin, A. M. Abdul Rani, A. A. Abdu Aliyu, M. G. Bryant, M. Danish and A. Ahmad, Bio-ceramic coatings adhesion and roughness of biomaterials through PMEDM: a comprehensive review, Mater. Manuf. Processes, 2020, 35, 1157-1180.

25 M. Khokhlova, M. Dykas, V. Krishnan-Kutty, A. Patra, T. Venkatesan and W. Prellier, Oxide thin films as bioactive coatings, J. Phys.: Condens. Matter, 2019, 31, 033001.

$26 \mathrm{X}$. Liu and C. Ding, Plasma sprayed wollastonite/ $\mathrm{TiO}_{2}$ composite coatings on titanium alloys, Biomaterials, 2002, 23, 4065-4077.

27 X. Zhao, G. Wang, H. Zheng, Z. Lu, X. Cheng and H. Zreiqat, Refining nanotopographical features on bone implant surfaces by altering surface chemical compositions, RSC Adv., 2014, 4, 54226-54234.

28 S. Park, J. Park, J. Heo, B. Y. Hong and J. Hong, Growth behaviors and biocidal properties of titanium dioxide films depending on nucleation duration in liquid phase deposition, Appl. Surf. Sci., 2017, 425, 547-552.

29 K. Lee, A. Mazare and P. Schmuki, One-dimensional titanium dioxide nanomaterials: nanotubes, Chem. Rev., 2014, 114, 9385-9454.

30 L. Bai, Y. Zhao, P. Chen, X. Zhang, X. Huang, Z. Du, R. Crawford, X. Yao, B. Tang, R. Hang and Y. Xiao, Targeting early healing phase with titania nanotube arrays on tunable diameters to accelerate bone regeneration and osseointegration, Small, 2021, 17, e2006287.

31 M. Yang, H. Liu, C. Qiu, I. Iatsunskyi, E. Coy, S. Moya, Z. Wang, W. Wu, X. Zhao and G. Wang, Electron transfer correlated antibacterial activity of biocompatible graphene Nanosheets- $\mathrm{TiO}_{2}$ coatings, Carbon, 2020, 166, 350-360. 
32 L. Bai, Z. Du, J. Du, W. Yao, J. Zhang, Z. Weng, S. Liu, Y. Zhao, Y. Liu, X. Zhang, X. Huang, X. Yao, R. Crawford, R. Hang, D. Huang, B. Tang and Y. Xiao, A multifaceted coating on titanium dictates osteoimmunomodulation and osteo/angio-genesis towards ameliorative osseointegration, Biomaterials, 2018, 162, 154-169.

33 L. Bai, Y. Liu, Z. Du, Z. Weng, W. Yao, X. Zhang, X. Huang, X. Yao, R. Crawford, R. Hang, D. Huang, B. Tang and Y. Xiao, Differential effect of hydroxyapatite nano-particle versus nano-rod decorated titanium micro-surface on osseointegration, Acta Biomater., 2018, 76, 344-358.

34 Z. Wang, Y. Niu, X. Tian, N. Yu, X. Yin, Z. Xing, Y. Li, L. Dong and C. Wang, Switching on and off macrophages by a "bridge-burning" coating improves bone-implant integration under osteoporosis, Adv. Funct. Mater., 2020, 31, 2007408.

35 Y. Shi, L. Wang, Y. Niu, N. Yu, P. Xing, L. Dong and C. Wang, Fungal component coating enhances titanium implant-bone integration, Adv. Funct. Mater., 2018, 28, 1804483.

36 R. S. B. Lee, S. M. Hamlet, H. J. Moon and S. Ivanovski, Reestablishment of macrophage homeostasis by titanium surface modification in type II diabetes promotes osseous healing, Biomaterials, 2021, 267, 120464.

37 L.-C. Zhang, L.-Y. Chen and L. Wang, Surface modification of titanium and titanium alloys: Technologies, developments, and future interests, Adv. Eng. Mater., 2020, 22, 1901258.

38 S. Devgan and S. S. Sidhu, Evolution of surface modification trends in bone related biomaterials: A review, Mater. Chem. Phys., 2019, 233, 68-78.

39 Y. Liu, B. Rath, M. Tingart and J. Eschweiler, Role of implants surface modification in osseointegration: A systematic review, J. Biomed. Mater. Res., Part A, 2020, 108, 470-484.

40 R. I. M. Asri, W. S. W. Harun, M. Samykano, N. A. C. Lah, S. A. C. Ghani, F. Tarlochan and M. R. Raza, Corrosion and surface modification on biocompatible metals: A review, Mater. Sci. Eng., C, 2017, 77, 1261-1274.

41 Y. Sasikumar, I. Karuppusamy and R. Nallaiyan, Surface modification methods for titanium and its alloys and their corrosion behavior in biological environment: A review, J. Bio- Tribo-Corros., 2019, 5, 36.

42 C. Hu, D. Ashok, D. R. Nisbet and V. Gautam, Bioinspired surface modification of orthopedic implants for bone tissue engineering, Biomaterials, 2019, 219, 119366.

43 H. Chouirfa, H. Bouloussa, V. Migonney and C. FalentinDaudré, Review of titanium surface modification techniques and coatings for antibacterial applications, Acta Biomater., 2019, 83, 37-54.

44 B. Bacchelli, G. Giavaresi, M. Franchi, D. Martini, V. De Pasquale, A. Trirè, M. Fini, R. Giardino and A. Ruggeri, Influence of a zirconia sandblasting treated surface on peri-implant bone healing: An experimental study in sheep, Acta Biomater., 2009, 5, 2246-2257.

45 V. Barranco, M. L. Escudero and M. C. García-Alonso, 3D, chemical and electrochemical characterization of blasted
TI6Al4V surfaces: Its influence on the corrosion behaviour, Electrochim. Acta, 2007, 52, 4374-4384.

46 A. Günay-Bulutsuz, Ö. Berrak, H. A. Yeprem, E. D. Arisan and M. E. Yurci, Biological responses of ultrafine grained pure titanium and their sand blasted surfaces, Mater. Sci. Eng., C, 2018, 91, 382-388.

47 T. C. Lowe, R. A. Reiss, P. E. Illescas, C. F. Davis, M. C. Connick and J. A. Sena, Effect of surface grain boundary density on preosteoblast proliferation on titanium, Mater. Res. Lett., 2020, 8, 239-246.

48 X. Shi, L. Xu, Q. Wang, Sunarso and L. Xu, Hydrothermal sterilization improves initial osteoblast responses on sandpaper-polished titanium, Materials, 2017, 10, 812.

49 X. Miao, D. Wang, L. Xu, J. Wang, D. Zeng, S. Lin, C. Huang, X. Liu and X. Jiang, The response of human osteoblasts, epithelial cells, fibroblasts, macrophages and oral bacteria to nanostructured titanium surfaces: a systematic study, Int. J. Nanomed., 2017, 12, 1415-1430.

50 Y. Wang, Z. Yu, K. Li and J. Hu, Effects of surface properties of titanium alloys modified by grinding, sandblasting and acidizing and nanosecond laser on cell proliferation and cytoskeleton, Appl. Surf. Sci., 2020, 501, 144279.

51 L. Łatka, L. Pawłowski, M. Winnicki, P. Sokołowski, A. Małachowska and S. Kozerski, Review of functionally graded thermal sprayed coatings, Appl. Sci., 2020, 10, 5153.

52 I. Ratha, P. Datta, V. K. Balla, S. K. Nandi and B. Kundu, Effect of doping in hydroxyapatite as coating material on biomedical implants by plasma spraying method: A review, Ceram. Int., 2021, 47, 4426-4445.

53 K. A. Khor, Y. W. Gu, D. Pan and P. Cheang, Microstructure and mechanical properties of plasma sprayed HA/YSZ/Ti-6Al4V composite coatings, Biomaterials, 2004, 25, 4009-4017.

54 A. Fomin, M. Fomina, V. Koshuro, I. Rodionov, A. Zakharevich and A. Skaptsov, Structure and mechanical properties of hydroxyapatite coatings produced on titanium using plasma spraying with induction preheating, Ceram. Int., 2017, 43, 11189-11196.

55 I. Ullah, M. A. Siddiqui, H. Liu, S. K. Kolawole, J. Zhang, S. Zhang, L. Ren and K. Yang, Mechanical, biological, and antibacterial characteristics of plasma-sprayed ( $\mathrm{Sr}, \mathrm{Zn}$ ) substituted hydroxyapatite coating, ACS Biomater. Sci. Eng., 2020, 6, 1355-1366.

56 D. Ke, A. A. Vu, A. Bandyopadhyay and S. Bose, Compositionally graded doped hydroxyapatite coating on titanium using laser and plasma spray deposition for bone implants, Acta Biomater., 2019, 84, 414-423.

57 D. Lahiri, A. P. Benaduce, F. Rouzaud, J. Solomon, A. K. Keshri, L. Kos and A. Agarwal, Wear behavior and in vitro cytotoxicity of wear debris generated from hydroxyapatite-carbon nanotube composite coating, J. Biomed. Mater. Res., Part A, 2011, 96, 1-12.

58 N. Sarkar and S. Bose, Controlled delivery of curcumin and vitamin $\mathrm{K} 2$ from hydroxyapatite-coated titanium implant for enhanced in vitro chemoprevention, osteogenesis, and in vivo osseointegration, ACS Appl. Mater. Interfaces, 2020, 12, 13644-13656. 
59 D. Cheng, Q. Liang, Y. Li, J. Fan, G. Wang, H. Pan and C. Ruan, Strontium incorporation improves the boneforming ability of scaffolds derived from porcine bone, Colloids Surf., B, 2018, 162, 279-287.

60 Z. Xu, H. Lu, J. Lu, C. Lv, X. Zhao and G. Wang, Enhanced osteogenic activity of Ti alloy implants by modulating strontium configuration in their surface oxide layers, $R S C$ Adv., 2018, 8, 3051-3060.

61 W. Zhang, G. Wang, Y. Liu, X. Zhao, D. Zou, C. Zhu, Y. Jin, Q. Huang, J. Sun, X. Liu, X. Jiang and H. Zreiqat, The synergistic effect of hierarchical micro/nano-topography and bioactive ions for enhanced osseointegration, Biomaterials, 2013, 34, 3184-3195.

62 G. Wang, X. Zhao, M. Möller and S. E. Moya, Interfacial reaction-driven formation of silica carbonate biomorphs with subcellular topographical features and their biological activity, ACS Appl. Mater. Interfaces, 2015, 7, 23412-23417.

63 Z. Xu, J. Long, N. Zhang, H. Cao, W. Tang, K. Shi, X. Wang, S. Moya, L. Duan, H. Pan, Y. Lai, D. Wang and G. Wang, Strong mineralization ability of strontium zinc silicate: Formation of a continuous biomorphic mineralized layer with enhanced osteogenic activity, Colloids Surf., B, 2019, 176, 420-430.

64 A. Abdal Dayem, M. K. Hossain, S. B. Lee, K. Kim, S. K. Saha, G. M. Yang, H. Y. Choi and S. G. Cho, The role of reactive oxygen species (ROS) in the biological activities of metallic nanoparticles, Int. J. Mol. Sci., 2017, 18, 120.

65 X. Zhao, L. You, T. Wang, X. Zhang, Z. Li, L. Ding, J. Li, C. Xiao, F. Han and B. Li, Enhanced osseointegration of titanium implants by surface modification with silicondoped titania nanotubes, Int. J. Nanomed., 2020, 15, 8583-8594.

66 H. Qin, H. Cao, Y. Zhao, C. Zhu, T. Cheng, Q. Wang, X. Peng, M. Cheng, J. Wang, G. Jin, Y. Jiang, X. Zhang, $\mathrm{X}$. Liu and P. K. Chu, In vitro and in vivo anti-biofilm effects of silver nanoparticles immobilized on titanium, Biomaterials, 2014, 35, 9114-9125.

67 J. Wang, J. Li, S. Qian, G. Guo, Q. Wang, J. Tang, H. Shen, X. Liu, X. Zhang and P. K. Chu, Antibacterial Surface Design of Titanium-Based Biomaterials for Enhanced Bacteria-Killing and Cell-Assisting Functions Against Periprosthetic Joint Infection, ACS Appl. Mater. Interfaces, 2016, 8, 11162-11178.

68 G. Wang, W. Jin, A. M. Qasim, A. Gao, X. Peng, W. Li, H. Feng and P. K. Chu, Antibacterial effects of titanium embedded with silver nanoparticles based on electrontransfer-induced reactive oxygen species, Biomaterials, 2017, 124, 25-34.

69 H. Cao, Y. Qiao, X. Liu, T. Lu, T. Cui, F. Meng and P. K. Chu, Electron storage mediated dark antibacterial action of bound silver nanoparticles: smaller is not always better, Acta Biomater., 2013, 9, 5100-5110.

70 Y. Zhao, H. Cao, H. Qin, T. Cheng, S. Qian, M. Cheng, X. Peng, J. Wang, Y. Zhang, G. Jin, X. Zhang, X. Liu and P. K. Chu, Balancing the osteogenic and antibacterial properties of titanium by codoping of $\mathrm{Mg}$ and $\mathrm{Ag}$ : $\mathrm{An}$ in vitro and in vivo study, ACS Appl. Mater. Interfaces, 2015, 7, 17826-17836.

71 H. C. Li, D. G. Wang, C. Hu, J. H. Dou, H. J. Yu and C. Z. Chen, Effect of $\mathrm{Na}_{2} \mathrm{O}$ and $\mathrm{ZnO}$ on the microstructure and properties of laser cladding derived $\mathrm{CaO}-\mathrm{SiO}_{2}$ ceramic coatings on titanium alloys, J. Colloid Interface Sci., 2021, 592, 498-508.

72 H. C. Li, D. G. Wang, C. Hu, J. H. Dou, H. J. Yu, C. Z. Chen and G. C. Gu, Microstructure, mechanical and biological properties of laser cladding derived $\mathrm{CaO}-\mathrm{SiO}_{2}-\mathrm{MgO}$ system ceramic coatings on titanium alloys, Appl. Surf. Sci., 2021, 548, 149296.

73 A. L. Raines, R. Olivares-Navarrete, M. Wieland, D. L. Cochran, Z. Schwartz and B. D. Boyan, Regulation of angiogenesis during osseointegration by titanium surface microstructure and energy, Biomaterials, 2010, 31, 4909-4917.

74 B. D. Boyan, S. Lossdorfer, L. Wang, G. Zhao, C. H. Lohmann, D. L. Cochran and Z. Schwartz, Osteoblasts generate an osteogenic microenvironment when grown on surfaces with rough microtopographies, Eur. Cells Mater., 2003, 6, 22-27.

75 R. A. Gittens, T. McLachlan, R. Olivares-Navarrete, Y. Cai, S. Berner, R. Tannenbaum, Z. Schwartz, K. H. Sandhage and B. D. Boyan, The effects of combined micron-/ submicron-scale surface roughness and nanoscale features on cell proliferation and differentiation, Biomaterials, 2011, 32, 3395-3403.

76 E. W. Zhang, Y. B. Wang, K. G. Shuai, F. Gao, Y. J. Bai, Y. Cheng, X. L. Xiong, Y. F. Zheng and S. C. Wei, In vitro and in vivo evaluation of SLA titanium surfaces with further alkali or hydrogen peroxide and heat treatment, Biomed. Mater., 2011, 6, 025001.

77 H. Liu, R. Liu, I. Ullah, S. Zhang, Z. Sun, L. Ren and K. Yang, Rough surface of copper-bearing titanium alloy with multifunctions of osteogenic ability and antibacterial activity, J. Mater. Sci. Technol., 2020, 48, 130-139.

78 A. Scarano, E. Crocetta, A. Quaranta and F. Lorusso, Influence of the thermal treatment to address a better osseointegration of Ti6Al4V dental implants: Histological and histomorphometrical study in a rabbit model, BioMed Res. Int., 2018, 2349698.

79 G. Wang, J. Li, K. Lv, W. Zhang, X. Ding, G. Yang, X. Liu and X. Jiang, Surface thermal oxidation on titanium implants to enhance osteogenic activity and in vivo osseointegration, Sci. Rep., 2016, 6, 31769.

80 G. A. Longhitano, M. A. Larosa, A. L. Jardini, C. A. D. C. Zavaglia and M. C. F. Ierardi, Correlation between microstructures and mechanical properties under tensile and compression tests of heat-treated Ti-6Al-4 V ELI alloy produced by additive manufacturing for biomedical applications, J. Mater. Process. Technol., 2018, 252, 202-210.

81 G. A. Longhitano, M. A. Arenas, A. Conde, M. A. Larosa, A. L. Jardini, C. A. D. C. Zavaglia and J. J. Damborenea, 
Heat treatments effects on functionalization and corrosion behavior of Ti-6Al-4V ELI alloy made by additive manufacturing, J. Alloys Compd., 2018, 765, 961-968.

82 J. Jenkins, J. Mantell, C. Neal, A. Gholinia, P. Verkade, A. H. Nobbs and B. Su, Antibacterial effects of nanopillar surfaces are mediated by cell impedance, penetration and induction of oxidative stress, Nat. Commun., 2020, 11, 1626.

83 M. Gu, L. Lv, F. Du, T. Niu, T. Chen, D. Xia, S. Wang, X. Zhao, J. Liu, Y. Liu, C. Xiong and Y. Zhou, Effects of thermal treatment on the adhesion strength and osteoinductive activity of single-layer graphene sheets on titanium substrates, Sci. Rep., 2018, 8, 8141.

84 S. Bose, D. Ke, A. A. Vu, A. Bandyopadhyay and S. B. Goodman, Thermal oxide layer enhances crystallinity and mechanical properties for plasma-sprayed hydroxyapatite biomedical coatings, ACS Appl. Mater. Interfaces, 2020, 12, 33465-33472.

85 Y. Dang, L. Zhang, W. Song, B. Chang, T. Han, Y. Zhang and L. Zhao, In vivo osseointegration of Ti implants with a strontium-containing nanotubular coating, Int. J. Nanomed., 2016, 11, 1003-1011.

86 Y. Zhang, K. Wang, Y. Song, E. Feng, K. Dong, Y. Han and T. Lu, Ca substitution of $\mathrm{Sr}$ in $\mathrm{Sr}$-doped $\mathrm{TiO}_{2}$ nanotube film on Ti surface for enhanced osteogenic activity, Appl. Surf. Sci., 2020, 528, 147055.

87 Z. Geng, X. Li, L. Ji, Z. Li, S. Zhu, Z. Cui, J. Wang, J. Cui, $\mathrm{X}$. Yang and C. Liu, A novel snail-inspired bionic design of titanium with strontium-substituted hydroxyapatite coating for promoting osseointegration, J. Mater. Sci. Technol., 2021, 79, 35-45.

88 N. Jiang, Z. Guo, D. Sun, Y. Li, Y. Yang, C. Chen, L. Zhang and S. Zhu, Promoting osseointegration of Ti Implants through micro/nanoscaled hierarchical Ti phosphate/Ti oxide hybrid coating, ACS Nano, 2018, 12, 7883-7891.

89 B. Cai, P. Tan, N. Jiang, Z. Guo, B. Ay, S. Li, Y. Hou, Y. Li, Y. You, L. Zhang and S. Zhu, Bioinspired fabrication of calcium-doped TiP coating with nanofibrous microstructure to accelerate osseointegration, Bioconjugate Chem., 2020, 31, 1641-1650.

90 E. B. Ansar, K. Ravikumar, S. Suresh Babu, F. B. Fernandez, M. Komath, B. Basu and P. R. Harikrishna, Varma, Inducing apatite pre-layer on titanium surface through hydrothermal processing for osseointegration, Mater. Sci. Eng., C, 2019, 105, 110019.

91 J. V. Wandiyanto, T. Tamanna, D. P. Linklater, V. K. Truong, M. Al Kobaisi, V. A. Baulin, S. Joudkazis, H. Thissen, R. J. Crawford and E. P. Ivanova, Tunable morphological changes of asymmetric titanium nanosheets with bactericidal properties, J. Colloid Interface Sci., 2020, 560, 572-580.

92 T. L. Clainche, D. Linklater, S. Wong, P. Le, S. Juodkazis, X. L. Guevel, J. L. Coll, E. P. Ivanova and V. Martel-Frachet, Mechano-bactericidal titanium surfaces for bone tissue engineering, ACS Appl. Mater. Interfaces, 2020, 12, 48272-48283.
93 V. K. Manivasagam and K. C. Popat, In Vitro Investigation of Hemocompatibility of Hydrothermally Treated Titanium and Titanium Alloy Surfaces, ACS Omega, 2020, 5, 8108-8120.

94 D. P. Linklater, S. Juodkazis, R. J. Crawford and E. P. Ivanova, Mechanical inactivation of Staphylococcus aureus and Pseudomonas aeruginosa by titanium substrata with hierarchical surface structures, Materialia, 2019, 5, 100197.

95 A. Cheng, W. B. Goodwin, B. M. deGlee, R. A. Gittens, J. P. Vernon, S. L. Hyzy, Z. Schwartz, K. H. Sandhage and B. D. Boyan, Surface modification of bulk titanium substrates for biomedical applications via low-temperature microwave hydrothermal oxidation, J. Biomed. Mater. Res., Part A, 2018, 106, 782-796.

96 X. Nie, S. Yin, W. Duan, Z. Zhao, L. Li and Z. Zhang, Recent Progress in Anodic Oxidation of $\mathrm{TiO}_{2}$ Nanotubes and Enhanced Photocatalytic Performance: A Short Review, NANO, 2021, 16, 2130002.

97 K. Das, A. Bandyopadhyay and S. Bose, Biocompatibility and in situ growth of $\mathrm{TiO}_{2}$ nanotubes on Ti using different electrolyte chemistry, J. Am. Ceram. Soc., 2008, 91, 2808-2814.

98 B. C. Ward and T. J. Webster, Increased functions of osteoblasts on nanophase metals, Mater. Sci. Eng., C, 2007, 27, 575-578.

99 T. J. Webster and J. U. Ejiofor, Increased osteoblast adhesion on nanophase metals: Ti, Ti6Al4V, and CoCrMo, Biomaterials, 2004, 25, 4731-4739.

100 S. Durdu, G. Cihan, E. Yalcin and A. Altinkok, Characterization and mechanical properties of $\mathrm{TiO}_{2}$ nanotubes formed on titanium by anodic oxidation, Ceram. Int., 2021, 47, 10972-10979.

101 M. Alijani, H. Sopha, S. Ng and J. M. Macak, High aspect ratio $\mathrm{TiO}_{2}$ nanotube layers obtained in a very short anodization time, Electrochim. Acta, 2021, 376, 138080.

102 I. P. Torres-Avila, I. I. Padilla-Martínez, N. PérezHernández, A. E. Bañuelos-Hernández, J. C. Velázquez, J. L. Castrejón-Flores and E. Hernández-Sánchez, Surface modification of the Ti-6Al-4V alloy by anodic oxidation and its effect on osteoarticular cell proliferation, Coatings, 2020, 10, 491.

103 B. Ren, Y. Wan, C. Liu, H. Wang, M. Yu, X. Zhang and Y. Huang, Improved osseointegration of 3D printed Ti-6Al$4 \mathrm{~V}$ implant with a hierarchical micro/nano surface topography: An in vitro and in vivo study, Mater. Sci. Eng., C, 2021, 118, 111505.

104 V. Zwilling, E. Darque-Ceretti, A. Boutry-Forveille, D. David, M.-Y. Perrin and M. Aucouturier, Structure and physicochemistry of anodic oxide films on titanium and TA6V alloy, Surf. Interface Anal., 1999, 27, 629-637.

105 S. Bodhak, S. Bose and A. Bandyopadhyay, Electrically polarized HAp-coated Ti: In vitro bone cell-material interactions, Acta Biomater., 2010, 6, 641-651.

106 A. Bandyopadhyay, A. Shivaram, I. Mitra and S. Bose, Electrically polarized $\mathrm{TiO}_{2}$ nanotubes on Ti implants to 
enhance early-stage osseointegration, Acta Biomater., 2019, 96, 686-693.

107 K. Cowden, M. F. Dias-Netipanyj and K. C. Popat, Effects of titania nanotube surfaces on osteogenic differentiation of human adipose-derived stem cells, Nanomedicine, 2019, 17, 380-390.

108 M. Y. Hsu, H. L. Hsu and J. J. J. O. T. E. S. Leu, TiO nanowires on anodic $\mathrm{TiO}_{2}$ nanotube arrays (TNWs/TNAs): Formation mechanism and photocatalytic performance, J. Electrochem. Soc., 2012, 159, H722.

109 V.-T. Nguyen, T.-C. Cheng, T.-H. Fang and M.-H. Li, The fabrication and characteristics of hydroxyapatite film grown on titanium alloy Ti-6Al-4V by anodic treatment, J. Mater. Res. Technol., 2020, 9, 4817-4825.

110 S.-G. Lim and H.-C. Choe, Bioactive apatite formation on PEO-treated Ti-6Al-4V alloy after 3rd anodic titanium oxidation, Appl. Surf. Sci., 2019, 484, 365-373.

111 L. Facchini, E. Magalini, P. Robotti, A. Molinari, S. H. Ges and K. J. R. P. J. Wissenbach, Ductility of a Ti-6Al-4V alloy produced by selective laser melting of prealloyed powders, Rapid Prototyp. J., 2010, 16, 450-459.

112 H. Zhang, J. Zhao, J. Liu, H. Qin, Z. Ren, G. L. Doll, Y. Dong and C. Ye, The effects of electrically-assisted ultrasonic nanocrystal surface modification on 3D-printed Ti-6Al-4V alloy, Addit. Manuf., 2018, 22, 60-68.

113 J. Wang, Y. Pan, R. Feng, H. Cui, B. Gong, L. Zhang, Z. Gao, X. Cui, H. Zhang and Z. Jia, Effect of electrolyte composition on the microstructure and bio-corrosion behavior of micro-arc oxidized coatings on biomedical Ti6Al4V alloy, J. Mater. Res. Technol., 2020, 9, 1477-1490.

114 G. Li, H. Cao, W. Zhang, X. Ding, G. Yang, Y. Qiao, X. Liu and X. Jiang, Enhanced osseointegration of hierarchical micro/nanotopographic titanium fabricated by microarc oxidation and electrochemical treatment, ACS Appl. Mater. Interfaces, 2016, 8, 3840-3852.

115 G. O. Alrabeah, P. Brett, J. C. Knowles and H. Petridis, The effect of metal ions released from different dental implantabutment couples on osteoblast function and secretion of bone resorbing mediators, J. Dent., 2017, 66, 91-101.

116 Q. M. Zhao, X. K. Li, S. Guo, N. Wang, W. W. Liu, L. Shi and Z. Guo, Osteogenic activity of a titanium surface modified with silicon-doped titanium dioxide, Mater. Sci. Eng., C, 2020, 110, 110682.

117 Y. Li, W. Wang, F. Yu, D. Wang, S. Guan, Y. Li and M. Qi, Characterization and cytocompatibility of hierarchical porous $\mathrm{TiO}_{2}$ coatings incorporated with calcium and strontium by one-step micro-arc oxidation, Mater. Sci. Eng., C, 2020, 109, 110610.

118 S. Durdu, S. L. Aktug, K. Korkmaz, E. Yalcin and S. Aktas, Fabrication, characterization and in vitro properties of silver-incorporated $\mathrm{TiO}_{2}$ coatings on titanium by thermal evaporation and micro-arc oxidation, Surf. Coat. Technol., 2018, 352, 600-608.

119 J. Ye, B. Li, M. Li, Y. Zheng, S. Wu and Y. Han, ROS induced bactericidal activity of amorphous Zn-doped titanium oxide coatings and enhanced osseointegration in bacteria-infected rat tibias, Acta Biomater., 2020, 107, 313-324.

120 X. Li, M. Wang, W. Zhang, Y. Bai, Y. Liu, J. Meng and L. Zhang, A magnesium-incorporated nanoporous titanium coating for rapid osseointegration, Int. J. Nanomed., 2020, 15, 6593-6603.

121 T. H. Qaid, S. Ramesh, F. Yusof, W. J. Basirun, Y. C. Ching, H. Chandran, S. Ramesh and S. Krishnasamy, Micro-arc oxidation of bioceramic coatings containing eggshellderived hydroxyapatite on titanium substrate, Ceram. Int., 2019, 45, 18371-18381.

122 D. Gregurec, G. Wang, R. H. Pires, M. Kosutic, T. Ludtke, M. Delcea and S. E. Moya, Bioinspired titanium coatings: self-assembly of collagen-alginate films for enhanced osseointegration, J. Mater. Chem. B, 2016, 4, 1978-1986.

123 Y. He, K. Xu, K. Li, Z. Yuan, Y. Ding, M. Chen, C. Lin, B. Tao, X. Li, G. Zhang, P. Liu and K. Cai, Improved osteointegration by SEW2871-encapsulated multilayers on microstructured titanium via macrophages recruitment and immunomodulation, Appl. Mater. Today, 2020, 20, 100673.

124 W. Chen, X. Shen, Y. Hu, K. Xu, Q. Ran, Y. Yu, L. Dai, Z. Yuan, L. Huang, T. Shen and K. Cai, Surface functionalization of titanium implants with chitosan-catechol conjugate for suppression of ROS-induced cells damage and improvement of osteogenesis, Biomaterials, 2017, 114, 82-96.

125 W. Chen, K. Xu, B. Tao, L. Dai, Y. Yu, C. Mu, X. Shen, Y. Hu, Y. He and K. Cai, Multilayered coating of titanium implants promotes coupled osteogenesis and angiogenesis in vitro and in vivo, Acta Biomater., 2018, 74, 489-504.

126 S. Zhao, Y. Xu, W. Xu, Z. Weng, F. Cao, X. Wan, T. Cui, Y. Yu, L. Liao and X. Wang, Tremella-like ZnO@Col-Idecorated titanium surfaces with dual-light-defined broad-spectrum antibacterial and triple osteogenic properties, ACS Appl. Mater. Interfaces, 2020, 12, 30044-30051.

127 J. Chen, G. Hu, T. Li, Y. Chen, M. Gao, Q. Li, L. Hao, Y. Jia, L. Wang and Y. Wang, Fusion peptide engineered "statically-versatile" titanium implant simultaneously enhancing anti-infection, vascularization and osseointegration, Biomaterials, 2021, 264, 120446.

128 H. Lee, S. M. Dellatore, W. M. Miller and P. B. Messersmith, Mussel-inspired surface chemistry for multifunctional coatings, Science, 2007, 318, 426-430.

129 H. Wang, C. Lin, X. Zhang, K. Lin, X. Wang and S. G. Shen, Mussel-inspired polydopamine coating: A general strategy to enhance osteogenic differentiation and osseointegration for diverse implants, ACS Appl. Mater. Interfaces, 2019, 11, 7615-7625.

130 S. Amin Yavari, S. M. Castenmiller, J. A. G. van Strijp and M. Croes, Combating implant infections: Shifting focus from bacteria to host, Adv. Mater., 2020, 32, 2002962.

131 S. H. Ku and C. B. Park, Human endothelial cell growth on mussel-inspired nanofiber scaffold for vascular tissue engineering, Biomaterials, 2010, 31, 9431-9437.

132 W.-B. Tsai, W.-T. Chen, H.-W. Chien, W.-H. Kuo and M.-J. Wang, Poly(dopamine) coating of scaffolds for articular 
cartilage tissue engineering, Acta Biomater., 2011, 7, 4187-4194.

133 H. Xu, G. Zhang, K. Xu, L. Wang, L. Yu, M. M. Q. Xing and X. Qiu, Mussel-inspired dual-functional PEG hydrogel inducing mineralization and inhibiting infection in maxillary bone reconstruction, Mater. Sci. Eng., C, 2018, 90, 379-386.

134 N. G. Rim, S. J. Kim, Y. M. Shin, I. Jun, D. W. Lim, J. H. Park and H. Shin, Mussel-inspired surface modification of poly(L-lactide) electrospun fibers for modulation of osteogenic differentiation of human mesenchymal stem cells, Colloids Surf., B, 2012, 91, 189-197.

135 E. Ko, J. S. Lee, H. Kim, S. Y. Yang, D. Yang, K. Yang, J. Lee, J. Shin, H. S. Yang, W. Ryu and S.-W. Cho, Electrospun silk fibroin nanofibrous scaffolds with two-stage hydroxyapatite functionalization for enhancing the osteogenic differentiation of human adipose-derived mesenchymal stem cells, ACS Appl. Mater. Interfaces, 2018, 10, 7614-7625.

136 S. Bose, N. Sarkar and D. Banerjee, Natural medicine delivery from biomedical devices to treat bone disorders: A review, Acta Biomater, 2021, 126, 63-91.

137 X. Song, F. Liu, C. Qiu, E. Coy, H. Liu, W. Aperador, K. Załęski, J. J. Li, W. Song, Z. Lu, H. Pan, L. Kong and G. Wang, Nanosurfacing Ti alloy by weak alkalinityactivated solid-state dewetting (AAD) and its biointerfacial enhancement effect, Mater. Horiz., 2021, 8, 912-924.

138 Z. Zhao, J. Chen, S. Guo, H. Tan, X. Lin and W. Huang, Influence of $\alpha / \beta$ interface phase on the tensile properties of laser cladding deposited Ti-6Al-4V titanium alloy, J. Mater. Sci. Technol., 2017, 33, 675-681.

139 J. Alayan, C. Vaquette, S. Saifzadeh, D. Hutmacher and S. Ivanovski, Comparison of early osseointegration of SLA $^{\circledR}$ and SLActive ${ }^{\circledR}$ implants in maxillary sinus augmentation: a pilot study, Clin. Oral. Implants Res., 2017, 28, 1325-1333.

140 J. Zhang, J. Liu, C. Wang, F. Chen, X. Wang and K. Lin, A comparative study of the osteogenic performance between the hierarchical micro/submicro-textured 3D-printed Ti6Al4V surface and the SLA surface, Bioact. Mater., 2020, 5, 9-16.

141 A. H. A. Qamheya, V. Arısan, Z. Mutlu, M. Karabaglı, M. Soluk Tekkeşin, K. Kara, A. Erol and S. Ersanlı, Thermal oxidation and hydrofluoric acid treatment on the sandblasted implant surface: A histologic histomorphometric and biomechanical study, Clin. Oral. Implants Res., 2018, 29, 741-755.

142 M. Zuldesmi, A. Waki, K. Kuroda and M. Okido, Hydrothermal treatment of titanium alloys for the enhancement of osteoconductivity, Mater. Sci. Eng., C, 2015, 49, 430-435.

143 J. Vishnu, V. K. Manivasagam, V. Gopal, C. Bartomeu Garcia, P. Hameed, G. Manivasagam and T. J. Webster, Hydrothermal treatment of etched titanium: A potential surface nano-modification technique for enhanced biocompatibility, Nanomedicine, 2019, 20, 102016.

144 X. Bai, X. Shi, L. Xu, F. Huang, C. Zheng, L. Xu, B. Li and Q. Wang, Effects of hydrothermal treatment on physicochemical and anticorrosion properties of titanium nitride coating on pure titanium, Appl. Surf. Sci., 2020, 507, 145030.

145 D. Khudhair, A. Bhatti, Y. Li, H. A. Hamedani, H. Garmestani, P. Hodgson and S. Nahavandi, Anodization parameters influencing the morphology and electrical properties of TiO2 nanotubes for living cell interfacing and investigations, Mater. Sci. Eng., C, 2016, 59, 1125-1142.

146 B. V. Krishna, S. Bose and A. Bandyopadhyay, Low stiffness porous Ti structures for load-bearing implants, Acta Biomater., 2007, 3, 997-1006.

147 W. Xue, B. V. Krishna, A. Bandyopadhyay and S. Bose, Processing and biocompatibility evaluation of laser processed porous titanium, Acta Biomater., 2007, 3, 1007-1018.

148 V. K. Balla, S. Banerjee, S. Bose and A. Bandyopadhyay, Direct laser processing of a tantalum coating on titanium for bone replacement structures, Acta Biomater., 2010, 6, 2329-2334.

149 V. K. Balla, S. Bodhak, S. Bose and A. Bandyopadhyay, Porous tantalum structures for bone implants: Fabrication, mechanical and in vitro biological properties, Acta Biomater., 2010, 6, 3349-3359.

150 S. Bose, S. F. Robertson and A. Bandyopadhyay, Surface modification of biomaterials and biomedical devices using additive manufacturing, Acta Biomater., 2018, 66, 6-22.

151 Q. Wang, P. Zhou, S. Liu, S. Attarilar, R. L.-W. Ma, Y. Zhong and L. Wang, Multi-scale surface treatments of titanium implants for rapid osseointegration: A review, Nanomaterials, 2020, 10, 1244.

152 I. Mitra, S. Bose, W. S. Dernell, N. Dasgupta, C. Eckstrand, J. Herrick, M. J. Yaszemski, S. B. Goodman and A. Bandyopadhyay, 3D Printing in alloy design to improve biocompatibility in metallic implants, Mater. Today, 2021, 45, 20-34.

153 A. Rifai, N. Tran, D. W. Lau, A. Elbourne, H. Zhan, A. D. Stacey, E. L. H. Mayes, A. Sarker, E. P. Ivanova, R. J. Crawford, P. A. Tran, B. C. Gibson, A. D. Greentree, E. Pirogova and K. Fox, Polycrystalline diamond coating of additively manufactured titanium for biomedical applications, ACS Appl. Mater. Interfaces, 2018, 10, 8474-8484.

154 H. Byun, Y. Bin Lee, E. M. Kim and H. Shin, Fabrication of size-controllable human mesenchymal stromal cell spheroids from micro-scaled cell sheets, Biofabrication, 2019, 11, 035025.

155 E. Gilabert-Chirivella, R. Pérez-Feito, C. Ribeiro, S. Ribeiro, D. M. Correia, M. L. González-Martín, J. M. Manero, S. Lanceros-Méndez, G. G. Ferrer and J. L. GómezRibelles, Chitosan patterning on titanium implants, Prog. Org. Coat., 2017, 111, 23-28.

156 S. Qiu, J. Ji, W. Sun, J. Pei, J. He, Y. Li, J. J. Li and G. Wang, Recent advances in surface manipulation using microcontact printing for biomedical applications, Smart Materials in Medicine, 2021, 2, 65-73.

157 B. Li, X. Xia, M. Guo, Y. Jiang, Y. Li, Z. Zhang, S. Liu, H. Li, C. Liang and H. Wang, Biological and antibacterial 
properties of the micro-nanostructured hydroxyapatite/ chitosan coating on titanium, Sci. Rep., 2019, 9, 14052.

158 D. Liu, C. He, Z. Liu and W. Xu, Gentamicin coating of nanotubular anodized titanium implant reduces implantrelated osteomyelitis and enhances bone biocompatibility in rabbits, Int. J. Nanomed., 2017, 12, 5461-5471.

159 M. Lilja, C. Lindahl, W. Xia, H. Engqvist and M. Strømme, The Effect of Si-Doping on the Release of Antibiotic from Hydroxyapatite Coatings, J. Biomater. Nanobiotechnol., 2013, 4, 237-241.

160 Z. Du, J. Chen, F. Yan and Y. Xiao, Effects of Simvastatin on bone healing around titanium implants in osteoporotic rats, Clin. Oral. Implants Res., 2009, 20, 145-150.

161 C. G. Park, M. Park, B. H. Kim, S. H. Lee, J. Y. Park, H. H. Park, K. Lee, H.-K. Seok and Y. B. Choy, Patterncoated titanium bone fixation plate for dual delivery of vancomycin and alendronate, Macromol. Res., 2017, 25, 756-762.

162 O. Janson, J. Sörensen, M. Strømme, H. Engqvist, P. Procter and K. Welch, Evaluation of an alkali-treated and hydroxyapatite-coated orthopedic implant loaded with tobramycin, J. Biomater. Appl., 2019, 34, 088532821986796.
163 L. Jia, F. Han, H. Wang, C. Zhu, Q. Guo, J. Li, Z. Zhao, Q. Zhang, X. Zhu and B. Li, Polydopamine-assisted surface modification for orthopaedic implants, J. Orthop. Translat., 2019, 17, 82-95.

164 T. Stich, F. Alagboso, T. Křenek, T. Kováŕík, V. Alt and D. Docheva, Implant-bone-interface: reviewing the impact of titanium surface modifications on osteogenic processes in vitro and in vivo, Bioeng. Transl. Med., 2021, e10239.

165 A. Civantos, E. Martínez-Campos, V. Ramos, C. Elvira, A. Gallardo and A. Abarrategi, Titanium coatings and surface modifications: Toward clinically useful bioactive implants, ACS Biomater. Sci. Eng., 2017, 3, 1245-1261.

166 G. Liu, M. Hirtz, H. Fuchs and Z. Zheng, Development of Dip-Pen Nanolithography (DPN) and Its Derivatives, Small, 2019, 15, 1900564.

167 K. T. M. Tran and T. D. Nguyen, Lithography-based methods to manufacture biomaterials at small scales, J. Sci.: Adv. Mater. Devices, 2017, 2, 1-14.

168 C. Liao, A. Wuethrich and M. Trau, A material odyssey for 3D nano/microstructures: two photon polymerization based nanolithography in bioapplications, Appl. Mater. Today, 2020, 19, 100635. 